\title{
Optimal Hedging Strategies and Interactions
}

Between Firms

\section{By}

Frédéric Loss

DISCUSSION PAPER 399

February 2002

\section{FINANCIAL MARKETS GROUP}

AN ESRC RESEARCH CENTRE

\section{LONDON SCHOOL OF ECONOMICS}

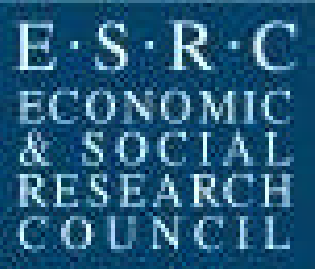

Any opinions expressed are those of the author and not necessarily those of the Financial Markets Group. 


\title{
Optimal Hedging Strategies and Interactions between Firms
}

\author{
Frédéric LoSS*
}

February 7, 2002

\begin{abstract}
This paper studies corporate risk management in a context with financial constraints and imperfect competition on the product market. We show that the interactions between firms heavily affect their hedging demand. As a general rule, the firms' hedging demand decreases with the correlation between firms' internal funds and investment opportunities. We show that when the hedging demand of a firm is high in the case where investments are strategic substitutes, its hedging demand is low in the case where investments are strategic complements, and vice versa. Finally, we also propose another interpretation of our model in terms of technical choice.
\end{abstract}

JEL Classification: G2, G3, D29

KEYWORDS: Hedging, Interactions between Firms, Credit Rationing

*GREMAQ and LSE. I am largely indebted to Bruno Jullien (my supervisor) for his detailed comments on this work and for his encouragements. Special thanks are due to Bruno Biais, Francois Boldron, Catherine Casamatta, Arnold Chassagnon, Denis Gromb, Antoine Faure-Grimaud, Hela Hadj Ali, Armel Jacques, Felix Muennich, Pierre Picard, Guillaume Plantin, Sebatien Pouget, Antoine Renucci, Sylvia Rosetto, Jean Tirole, Raoul Turtle, as well as participants at the IDEI Finance work group on Corporate Finance and Industrial Organization and at the Toulouse University young researchers seminar. I also would like to thank participants at the EEA meeting (Bozen-Bolzano 2000), the EARIE meeting (Lausanne 2000), the EGRIE meeting (Rome 2000) and the "Ecole de printemps" (Aix en Provence 2000). All remaining errors are mine. 


\section{Introduction}

To a large extent, the study of corporate risk management has been conducted assuming that the corporation is risk-averse. But, even if risk aversion can explain some hedging demand, it cannot explain why shareholders who can diversify their own portfolio outside the firm choose a positive hedging demand in a world with low individual transaction costs. Froot, Scharfstein and Stein (1993), in a setting of risk-neutral agents and of imperfect financial markets, propose a model in which the optimal risk management policy is affected by future investment opportunities. Hedging activity is undertaken as a tool to coordinate corporate investments and financial policies. In their empirical survey of the determinants of corporate hedging, Nance, Smith and Smithson (1993), Géczy, M inton and Schrand (1997) report that firms with greater growth opportunities and tighter financial constraints are more likely to hedge. This is in line with the previous prediction. When firms interact in the product market, investment opportunities depend on their competitors' behavior. The main goal of this paper is to understand how the externalities between firms affect their optimal hedging policy. We also propose some comparative statics for a given hedging policy of the other competitor and at the equilibrium.

We consider a model with three dates: date 0 , date 1 and date 2 . At date 0 , each firm invests its initial endowment of cash in a risky project which generates a new risky amount of cash at date 1 . At date 1 , we consider a duopoly framework in which firms face financial constraints arising from a moral-hazard problem (see Holmström and Tirole (1998)). In such a model, a firm's borrowing capacity is entirely determined by its internal funds. Here, these internal funds correspond to the date 1 new amount of cash. Finally, at date 2 the returns of the duopoly game of date 1 are realized. Date 1 new amount of cash is thus fundamental for each firm, and in this paper we determine the firms' optimal hedging policy of this date 1 new amount of cash. We examine this question in three cases of particular interest. The first case is when the risks which affect the date 1 amount of cash of each firm are perfectly correlated. The second case is when they are independent and the third case is when they are perfectly negatively correlated. We conduct our analysis when firms' investment are either strategic substitute or 
strategic complement.

In the case where investments are strategic substitutes, it is detrimental to a firm when the other firm has a high date 1 amount of cash. That is, the higher is the other firm's date 1 amount of cash, the lower is the firm's investment opportunities. Thus, when the risks are perfectly correlated, the firms' investment opportunities are higher when the firms' date 1 amount of cash are lower. Investment opportunities and date 1 amounts of cash are perfectly negatively correlated. Consequently, the hedging demand is high. When the risks are independent, there is no link between the investment opportunities and the firms' date 1 amounts of cash. Thus, the interactions between firms have no impact on their hedging demands. When the risks are perfectly negatively correlated, the investment opportunities are the higher when the firms' date 1 amounts of cash are the higher. The investment opportunities and the firms' date 1 amounts of cash are perfectly correlated. Thus, the firms' hedging demand is low. Consequently, in the substitute case, the firms' hedging demand is higher when the risks are perfectly correlated than when the risks are independent, and the lowest when the risks are perfectly negatively correlated.

In the case where investments are strategic complements, it is beneficial to one firm when the other firm has a high date 1 amount of cash. That is, the higher is the other firm's date 1 amount of cash, the higher is the firm's investment opportunities. Therefore, and contrary to the previous case, the firms' hedging demand is higher when the risks are perfectly negatively correlated than when the risks are independent, and the lowest when the risks are perfectly correlated.

This paper is related to corporate risk management analysis and imperfect competition. It is thereby connected to two strands of the literature:

In the Modigliani-Miller paradigm, hedging activities do not change the firm's value. Since 1958, many contributions have found situations in which the Modigliani-Miller theorem does not hold: in the presence of taxes, contracting costs, cost of bankruptcy or more generally when capital market imperfections make externally obtained funds more expensive than those generated internally.

Indeed a number of potential rationales for hedging have been put forward (e.g. Smith and 
Stulz (1985) and Mayers and Smith $(1982,1987))$. But these authors have focused on rationales for hedging rather than on how much or what sort of hedging is optimal for a firm. Froot, Scharfstein and Stein (1993) address this last question. They consider that external sources of financing are more costly than internally generated funds. In this setting, by hedging the firm can economize on future transaction costs. Then, they compute the optimal hedging strategy in a way to coordinate investments and financial policies. Holmström and Tirole (1999) go in the same direction. They show that firms should be isolated from all shocks that can be costlessly hedged in markets in order to reduce variability in investment rules. Our paper still characterizes the firms' optimal hedging strategy but with a different goal. We try to understand how the optimal hedging strategy changes depending on the links between the risks borne by the firms and on the interactions between firms.

A second strand of the literature tried to analyze what factors make a firm tougher or weaker in response to an increase in a variable by the other firm (cf. Fudenberg-T irole 1984). Bulow, Geanakoplos and Klemperer (1985) have shown that it depends on the interactions between firms. Our paper is closely connected to this literature because we show that the firms' interactions impact heavily on their hedging strategies. Indeed, the results found for the case where investments are strategic substitutes are reversed when we consider the case where investments are strategic complements.

The structure of the paper is as follows. Section 2 presents the model in terms of hedging choice and propose another interpretation of it in terms of technical choice. Section 3 presents the results for the substitute case (investments are strategic substitutes). Section 4 sketches the results for the complement case (investments are strategic complements). Section 5 concludes and mathematical proofs are in the appendix. 


\section{The model}

The economy is composed by two types of agents: two firms (firms 1 and 2) and lenders. There are three dates, $t=0,1,2$. All parties are risk neutral and protected by limited liability so that no one can end up with a negative cash position.

To characterize the hedging demand, we consider that there is credit rationing on the credit market at date 1. A nother way to induce a hedging demand is to consider that there are bankruptcy costs, convex tax functions or more generally, as in Froot et al (1993), to assume that external sources of financing are more expensive than internal ones. In this paper, we choose to link the hedging demand to an endogenous problem of credit rationing at date 1.

\section{$2.1 \quad$ Date 0}

\subsubsection{The firms}

At date 0 , we assume that firms cannot raise external finance. Each firm $i$ (with $i=1,2$ ) is endowed with an initial amount of cash $A_{i 0}$ and has the possibility to invest in a project which yields a random return $\widetilde{p}_{i}$ per unit of investment at date 1 . We assume that $\widetilde{p}_{i}$ which corresponds to the spot price at date 1 of the firm $i^{\prime} s$ project of date 0 , is equal to:

$$
\widetilde{p}_{i}=a+\varepsilon_{i}
$$

where $a$ is a constant and $\varepsilon_{i}$ denotes a negative shock which follows a normal law. Finally, we assume that the couple $\left(\widetilde{p}_{1} ; \widetilde{p}_{2}\right)$ follows a bivariate normal law with respective means $\mathbb{E} \widetilde{p}_{1}, \mathbb{E} \widetilde{p}_{2}$, respective variance $\sigma_{1}^{2}, \sigma_{2}^{2}$ and coefficient of correlation $\rho$.

Firms are run by risk neutral entrepreneurs ${ }^{1}$ who have to simultaneously choose the optimal hedging policy of the firm. ${ }^{2}$ Either the entrepreneur of firm $i$ decides not to hedge and the return is $\widetilde{p}_{i}$ per unit of investment at date 1 , or the entrepreneur prefers to hedge and the safe return is $p$ per unit of investment at date $1 .^{3}$ We assume that the risk borne by the firm is not fully

\footnotetext{
${ }^{1}$ In this article, a firm corresponds to an entrepreneur. Therefore, we can equivalently deal with a firm or with an entrepreneur.

${ }^{2}$ We focus on linear hedging strategies (for example forward sales) in this article.

${ }^{3}$ We implicitly assume that $p>1$. Otherwise, the entrepreneur would prefer to keep cash from date 0 to date 1 , rather than to hedge the result of the project of date 0 .
} 
diversifiable and that hedging is costly. In other words and as a short cup, we assume that:

$$
p<\mathbb{E} \widetilde{p}_{i}
$$

As usual, $\mathbb{E} \widetilde{p}_{i}-p$ is called the hedging risk premium.

We denote $h_{i} \in[0 ; 1]$ the level of hedging chosen by the entrepreneur of firm $i$. The return at date 1 for firm $i, A_{i 1}$ amounts to:

$$
A_{i 1}=A_{i 0}\left(p h_{i}+\left(1-h_{i}\right) \widetilde{p}_{i}\right)
$$

We assume that $A_{i 0}, \widetilde{p}_{i}$ and $h_{i}$ are observable.

Remark 1 At date 0, we assume that firms cannot raise external finance. This assumption is without loss of generality in our setting. Even if firms were allowed to borrow at date 0 with the intention of investing more than $A_{i 0}$ in the project of date 0 , the return at date 1 would still be randomly distributed. Since we suppose that there is credit rationing at date 1, this possibility would not change the hedging demand. Thus, to simplify, we consider that at date 0 it is not possible to invest more than the endowment of cash $A_{i 0}$ in the project.

The model of date 1 and 2 is an extension of the Holmström and Tirole's continuous investment model (1998) (see also Tirole 1996).

\section{$2.2 \quad$ Date 1}

At date 1, we assume that firms can raise external finance from lenders.

\subsubsection{The firms}

At date 1 , each firm has the possibility to invest in a new project. The project of date 1 , if undertaken, either succeeds or fails. The probability of success is denoted by $P$. If it succeeds the project of date 1 yields a verifiable return which depends on the investments of both firms, $\pi_{i}\left(I_{i}, I_{j}\right)$ at date 2 . This function is assumed to be increasing and concave in $I_{i}$. In case of failure the return is zero. The project is subject to moral hazard in the sense that the probability of success depends on the behavior of the entrepreneur who runs the firm. The entrepreneur can 
behave or misbehave. Behaving yields a probability of success $P=1$ and no private benefit for the entrepreneur. On the other hand, misbehaving yields a smaller probability of success $P=P_{L}<1$, but the entrepreneur receives a private benefit proportional to the investment, $B I_{i}>0 .{ }^{4}$

To capture the idea of credit rationing, we assume that the marginal revenue of the project is always higher than 1 . This means that without any constraint the entrepreneur would like to invest an infinite level. At date 1 , the entrepreneur of firm $i$ is endowed with the amount $A_{i 1}$ of cash (see eq (1)). Thus, since he wants to invest an infinite level he has to borrow from lenders. The problem of credit rationing arises from the moral hazard problem. We assume that the project's net present value is positive only if the entrepreneur behaves:

$$
\pi_{i}\left(I_{i}, I_{j}\right)-I_{i}>0>P_{L} \pi_{i}\left(I_{i}, I_{j}\right)+B I_{i}-I_{i}
$$

Therefore, a loan agreement must be careful to preserve enough of a stake for the entrepreneur in the project so that he prefers to behave. ${ }^{5}$ This is precisely because the entrepreneur has to receive incentives so as to behave that he is not able to invest an infinite level in the project of date $1 .{ }^{6}$

\subsubsection{The lenders}

Lenders behave competitively in the sense that the loan, if any, makes zero profit. That is, we consider that several prospective lenders compete for issuing a loan to the borrower, and that if the most attractive loan offer made a positive profit, the borrower could turn to an alternative lender and offer to switch for a slightly lower interest rate. We use the plural "lenders" even though a single lender may turn out to finance the entire loan, because lending is a passive and anonymous activity in this article.

Let us now determine the date 1 optimal loan contract.

\footnotetext{
${ }^{4}$ Another interpretation of $B$ is in terms of effort. $B$ then, represents the disutility of effort saved by the entrepreneur when he misbehaves.

${ }^{5}$ Since entrepreneurs are protected by limited liability, "preserve enough of the stake for the entrepreneur" them requires the design of an incentive mechanism. Indeed, even if the project fails, which perfectly reveals that the entrepreneur was mishaving, the latter cannot be hanged or sent to jail.

${ }^{6}$ See below for more details on that point.
} 


\subsubsection{The date1 optimal loan contract}

The contract between the lender and the entrepreneur is a revenue sharing rule specifying what fraction of the revenue accrues to each party in the two states of the world. The entrepreneur receives $R_{b i}$ and lenders: $\pi_{i}\left(I_{i}, I_{j}\right)-R_{b i}$. A financing contract at date 1 is then defined by the couple $\left(R_{b i} ; I_{i}\right)$.

Since the project has a positive NPV only if the entrepreneur behaves, the contract should provide him the incentives to do so.

The maximization problem of the entrepreneur can be written as follows

$$
\begin{aligned}
& \max _{R_{b i}} R_{b i}-A_{i 1} \\
& \text { st }\left\{\begin{aligned}
& \pi_{i}\left(I_{i}, I_{j}\right)-R_{b i} \geq I_{i}-A_{i 1}\left(I R_{i}\right)_{l} \\
& R_{b i} \geq \frac{B I_{i}}{1-P_{L}}\left(I C_{i}\right)_{b}
\end{aligned}\right.
\end{aligned}
$$

B ecause lenders are competitive, their participation constraint is binding. Consequently, the entrepreneur receives the entire social surplus of the project. He wants to invest an infinite level since we assumed that the marginal revenue of the project is always higher than 1. But, because his incentive compatibility constraint must be satisfied, his investment is limited. Therefore, to maximize the level of investment and his expected revenue, the entrepreneur chooses to bind his incentive compatibility constraint, $\left(I C_{i}\right)_{b}$.

The second best investment level of each firm is given by the following system of two implicit equations

$$
\left\{\begin{array}{l}
\pi_{1}\left(I_{1}, I_{2}\right)-I_{1}=\frac{B I_{1}}{1-P_{L}}-A_{11} \\
\pi_{2}\left(I_{1}, I_{2}\right)-I_{2}=\frac{B I_{2}}{1-P_{L}}-A_{21}
\end{array}\right.
$$

Each investment level is a function of the date 1 amounts of cash, denoted $I_{i}\left(A_{i 1}, A_{j 1}\right)$. The characterization of the investment level is illustrated in figure 1. 


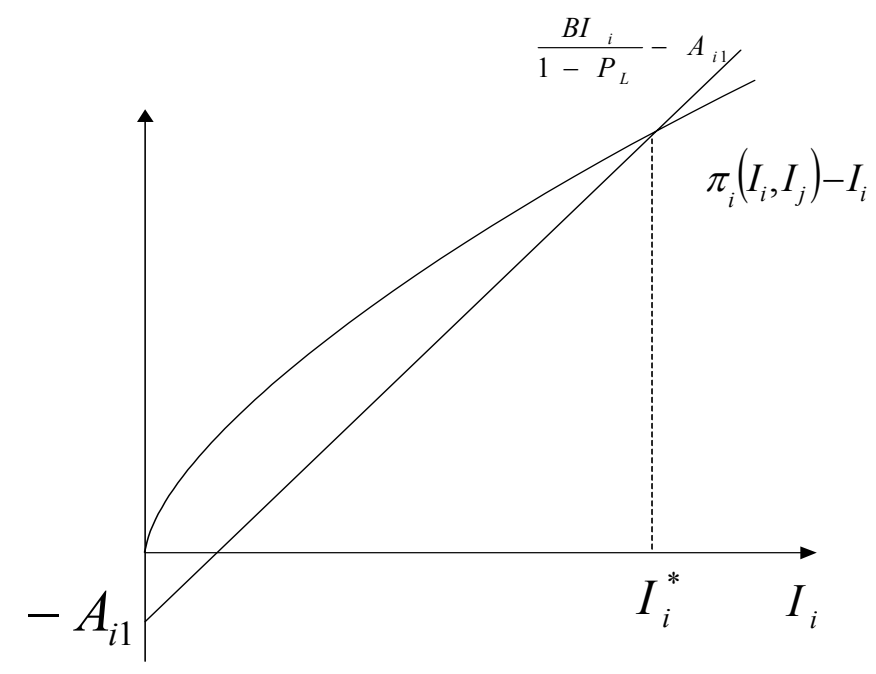

Figure 1

\section{$2.3 \quad$ Date 2}

The returns of the project of date 1 are realized, and claims are settled between firms and lenders.

The timing is summarized just below.

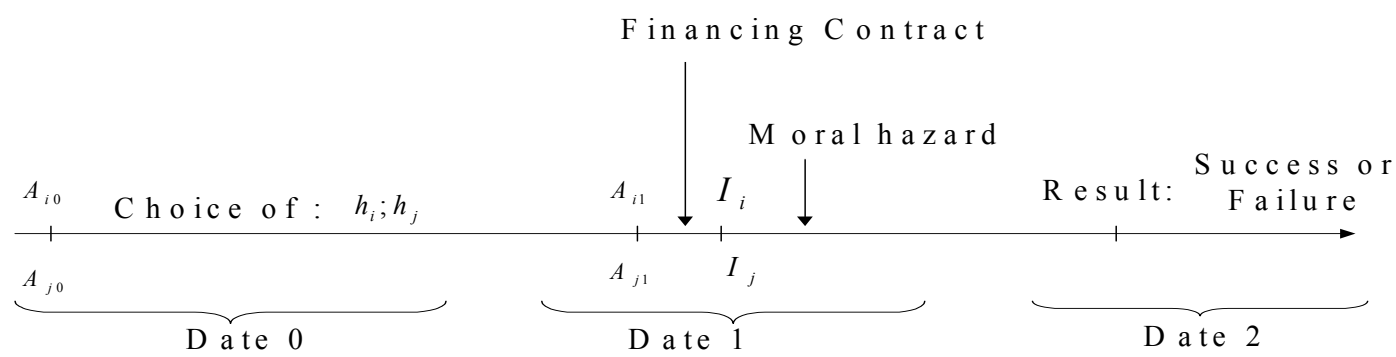


In this model, the investment of one firm depends on his date 1 amount of cash. Thus, we define a value function for each firm which depends on the date 1 amount of cash of both firms $V_{i}\left(A_{i 1} ; A_{j 1}\right)$ which we will use in the rest of the paper.

Definition 1 We define the value function $V_{i}\left(A_{i 1} ; A_{j 1}\right)$ by:

$$
\begin{array}{r}
V_{i}\left(A_{i 1} ; A_{j 1}\right): I R^{2} \rightarrow I R \text { twice continuously differentiable } \\
\text { such that } V_{i}\left(A_{i 1} ; A_{j 1}\right) \equiv \pi_{i}\left(I_{i}\left(A_{i 1}, A_{j 1}\right), I_{j}\left(A_{i 1}, A_{j 1}\right)\right)-I_{i}\left(A_{i 1}, A_{j 1}\right)
\end{array}
$$

The value function $V_{i}\left(A_{i 1} ; A_{j 1}\right)$ depends on the date 1 competition between firms. But $A_{i 1}$ and $A_{j 1}$ are not the strategic variables. The strategic variables are the levels of investment $I_{i}$ and $I_{j}$. The following proposition makes a link with the traditional definition introduced by Bulow et al (1985) of strategic substitutes vs strategic complements:

Let $\pi_{i}\left(I_{i}, I_{j}\right)$ be the firm $i$ 's profit function and $I_{i}$ its strategic variable.

On the one hand, if a marginal increase in the firm $j$ 's strategic variable $\left(I_{j}\right)$ decreases the firm $i^{\prime}$ s marginal profit $\left(\frac{\partial^{2} \pi_{i}\left(I_{i}, I_{j}\right)}{\partial I_{i} \partial I_{j}}<0\right)$ we say that $I_{i}$ and $I_{j}$ are strategic substitutes.

On the other hand, if a marginal increase in the firm $j$ 's strategic variable $\left(I_{j}\right)$ increases the firm $i$ 's marginal profit $\left(\frac{\partial^{2} \pi_{i}\left(I_{i}, I_{j}\right)}{\partial I_{i} \partial I_{j}}>0\right)$ we say that $I_{i}$ and $I_{j}$ are strategic complements.

Proposition 1 For $\frac{\partial^{2} \pi_{j}}{\partial I_{j} \partial I_{i}}, \frac{\partial^{2} \pi_{i}}{\partial I_{j}^{2}}, \frac{\partial^{2} \pi_{i}}{\partial I_{j} \partial I_{i}}, \frac{\partial^{2} \pi_{j}}{\partial I_{j}^{2}}, \frac{\partial^{2} \pi_{j}}{\partial I_{i}^{2}}$ bounded and $\frac{\partial \pi_{j}}{\partial I_{i}}, \frac{\partial \pi_{i}}{\partial I_{j}}$ sufficiently low, we have:

- $V_{i}\left(A_{i 1} ; A_{j 1}\right)$ increasing and concave in $A_{i 1}$

- if $I_{i}$ and $I_{j}$ are strategic substitutes, then $\frac{\partial^{2} V_{i}\left(A_{i 1} ; A_{j 1}\right)}{\partial A_{i 1} \partial A_{j 1}}<0$

- if $I_{i}$ and $I_{j}$ are strategic complements, then $\frac{\partial^{2} V_{i}\left(A_{i 1} ; A_{j 1}\right)}{\partial A_{i 1} \partial A_{j 1}}>0$

\section{Proof. see appendix 1}

For mathematical convenience, in the rest of the article, we restrict ourselves to the case where the value function $V_{i}\left(A_{i 1} ; A_{j 1}\right)$ is quadratic. This case represents a second order approximation of all other functions. 


\subsection{The production choice interpretation}

Our framework can also be applied to firms facing a production rather than an hedging choice. $A_{i 0}$ is then a stock of intermediate goods. Date 0 is an intermediate date during which the final good is produced. Each firm can choose between two technological processes to produce its final good. The first technology is risky. It yields a random production $\widetilde{q}_{i}$ per unit of investment at date 1. The second technology is not risky and yields a safe production $q$ per unit of investment.

Moreover and as above, we assume that

$$
q<\mathbb{E} \widetilde{q}_{i}
$$

Denoting by $h_{i}$ the firm $i$ 's safe production level, the quantity of final good at date $1 A_{i 1}$ can be written

$$
A_{i 1}=A_{i 0}\left(q h_{i}+\left(1-h_{i}\right) \widetilde{q}_{i}\right)
$$

At date 1 a differentiated product Cournot game is played. Both firms sell their production $A_{i 1}$ on the same market. Finally, profits are realized at date 2 . Consequently, the firm $i$ 's profit function can be written as follows:

$$
\begin{aligned}
\pi_{i}\left(A_{i 1}, A_{j 1}\right) & =\Pi\left(A_{i 1}+A_{j 1}\right) A_{i 1} \\
& \text { where } \Pi\left(A_{i 1}+A_{j 1}\right) \text { is the inverse demand function }
\end{aligned}
$$

Thus here, we define the value function $V_{i}\left(A_{i 1} ; A_{j 1}\right)$ by:

$$
V_{i}\left(A_{i 1} ; A_{j 1}\right): I R^{2} \rightarrow I R \text { twice continuously differentiable }
$$

such that $V_{i}\left(A_{i 1} ; A_{j 1}\right) \equiv \Pi\left(A_{i 1}+A_{j 1}\right) A_{i 1}$ 
The timing is as described below

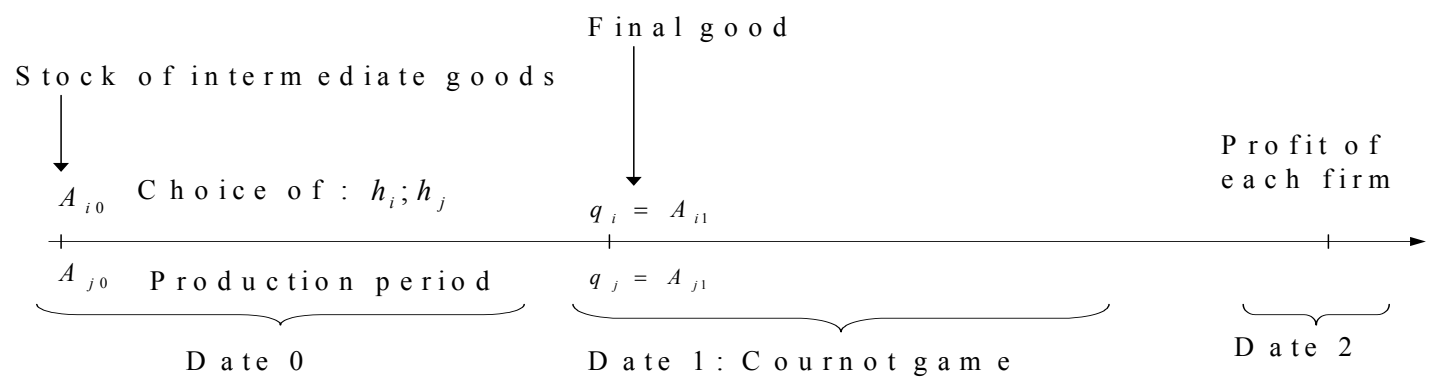

We assume that $V_{i}\left(A_{i 1}, A_{j 1}\right)$ is increasing and concave in $A_{i 1}$. We also restrict ourselves to the case where the value function $V_{i}\left(A_{i 1} ; A_{j 1}\right)$ is quadratic. Here, this case can exactly be generated, if we consider a differentiated products Cournot model with linear demand functions. Finally, we define strategic substitutability vs strategic complementarity in the usual way as described above. We can note that in the production choice interpretation, $A_{i 1}$ and $A_{j 1}$ are the strategic variables. Thus, we do not need to make a statement similar to proposition 1.

To fix ideas we deal only with the hedging interpretation in the rest of the paper. The production interpretation can equivalently be made simply by interpreting $h_{i}$ as the firm $i$ 's date 0 safe production level rather than as the firm $i$ 's date 0 hedging level.

\section{Optimal hedging strategies}

As we said above, in the hedging interpretation the strategic variables are the levels of investment $I_{i}$ and $I_{j}$ and not the firms' date 1 amount of cash. Thus, on the one hand, we refer to the substitute case if the firm $i$ 's marginal value of date 1 is decreasing with respect to the firm $j$ 's date 1 amount of cash. On the other hand, if the firm $i^{\prime}$ s marginal value of date 1 is increasing with respect to the firm $j$ 's date 1 amount of cash, we speak about the complement case.

We concentrate ourselves on three particular cases. The first case is when the shocks which affect the spot prices $\widetilde{p}_{1}$ and $\widetilde{p}_{2}$ are perfectly correlated $(\rho=1)$. We call this case the aggregated 
shocks case. For example, we could think about a raw materials shock for two firms inside the same industry as in Shleifer and V ishny (1992). ${ }^{7}$ The second is when the shocks which affect the spot prices are independent $(\rho=0)$. We call this case the independent shocks case. For example, we could consider a fire risk for two firms geographically distant one from the other. Finally, the last case we consider is when the shocks which affect the spot prices are perfectly negatively correlated $(\rho=-1)$. This last case is called, the perfectly negatively correlated shocks case. For instance, we could consider a shock on the consumers' preferences which shifts demand from one firm to the other.

At date 0 , the entrepreneur of firm $i$ chooses the optimal hedging level $h_{i}^{*}$ which maximize the firm $i$ 's date 1 expected value under two constraints which indicate how the firms' date 1 amounts of cash depend on their date 0 hedging choices

$$
\begin{aligned}
& h_{i}^{*} \in \underset{h_{i}}{\arg \max } \mathbb{E} V_{i}\left(A_{i 1}, A_{j 1}\right) \\
& \text { st }\left\{\begin{array}{l}
A_{i 1}=A_{i 0}\left(p h_{i}+\left(1-h_{i}\right) \widetilde{p}_{i}\right) \\
A_{j 1}=A_{j 0}\left(p h_{j}+\left(1-h_{j}\right) \widetilde{p}_{j}\right)
\end{array}\right.
\end{aligned}
$$

To derive the optimal hedging strategies, we compute the first order condition of the above program and we apply the Rubinstein (1976) rule. The calculations are detailed in appendix 2. Finally we find:

$$
-\operatorname{cov}\left(\frac{\partial V_{i}}{\partial A_{i 1}} ; \widetilde{p}_{i}\right)=\mathbb{E}\left[\frac{\partial V_{i}}{\partial A_{i 1}}\right]\left(\mathbb{E} \widetilde{p}_{i}-p\right)
$$

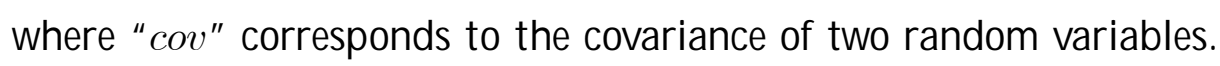

This condition indicates that the optimal hedging level restricts the covariance between the marginal value function and the random variable $\widetilde{p}_{i}$ to a precise value. This value corresponds to the average of the marginal value function, multiplied by the risk premium.

Remark 2 The optimal hedging level would insulate the marginal value function of $V_{i}\left(\frac{\partial V_{i}}{\partial A_{i 1}}\right)$, from fluctuations in the random variable $\widetilde{p}_{i}$ if there were no risk premium (like in the paper of

\footnotetext{
${ }^{7}$ example: the oil shock in 1973 for oil companies.
} 
Froot et al (1993)). Notice that it is not necessarily the same as insulating the total value of the firm $\left(V_{i}\right)$.

We can already notice that if the marginal value function of $V_{i}$ was independent of $\widetilde{p}_{i}$ ( $V_{i}$ linear), the first order condition indicates that $h_{i}$ would be equal to 0 , since we do not permit short sales.

On the other hand, if the covariance between the marginal value of $V_{i}$ and $\widetilde{p}_{i}$ is very high $\left(\frac{\partial^{2} V_{i}}{\partial A_{i 1}^{2}}\right.$ very high $)$, the first order condition indicates that $h_{i}$ would tend to 1.

We find the following expression for the reaction function $h_{i}\left(h_{j}\right) . h_{i}\left(h_{j}\right)$ corresponds to firm $i$ 's chosen hedging level, for a given firm $j$ 's hedging level.

Lemma 1 For $\rho \in\{-1,0,1\}$ we have :

$$
h_{i}\left(h_{j}\right)=1+\underbrace{\rho \frac{A_{j 0}}{A_{i 0}} \frac{\mathbb{E}\left(\frac{\partial^{2} V_{i}}{\partial A_{i 1} \partial A_{j 1}}\right)}{\mathbb{E}\left(\frac{\partial^{2} V_{i}}{\partial A_{i 1}^{2}}\right)} \frac{\sigma_{j}}{\sigma_{i}}\left(1-h_{j}\right)}_{\text {term } 1} \underbrace{+\frac{1}{A_{i 0}} \frac{\mathbb{E}\left(\frac{\partial V_{i}}{\partial A_{i 1}}\right)}{\mathbb{E}\left(\frac{\partial^{2} V_{i}}{\partial A_{i 1}^{2}}\right)} \frac{\mathbb{E} \widetilde{p}_{i}-p}{\sigma_{i}^{2}}}_{\text {term } 2}
$$

Proof. see appendix 2

The reaction functions are composed of two terms.

The first term reflects the interactions between the two firms. The sign of the interactions depends on the sign of the cross derivative $\frac{\partial^{2} V_{i}}{\partial A_{i 1} \partial A_{j 1}}$. This term corresponds to the expression which minimizes the "firm $i$ 's date 1 amount of cash balanced variance" (see appendix 3 for a proof). We call this term the interaction effect.

Thus, when firm $i$ 's value function depends on what firm(s) $j$ does (do), like in the duopolistic or more generally in the oligopolistic case, the nature of the links between firms is an important element of the hedging demand.

The second term expresses the trade off between the risk premium and the insurance demand due to the concavity of the value function $V_{i}$. This term depends neither on the cross derivative of the value function nor on the correlation coefficient. ${ }^{8}$ The higher is the risk premium, the

\footnotetext{
${ }^{8}$ In the finance literature, this term is called the speculative demand.
} 
lower is the hedging demand. If there is no risk premium, this term disappears. On the other hand, the hedging demand increases with the concavity of the value function $V_{i}$. We call this term the risk premium effect. Moreover, as a benchmark we can notice that in the case of a monopoly, only this effect would matter since the interaction effect would disappear.

For reading convenience, we are going to analyze the substitutes case. We deal with the complement case in a complementary section. ${ }^{9}$

\subsection{The substitute case}

In such a case, at date 1 it is detrimental to one firm (for example for firm $i$ ) when the date 1 amount of cash of its rival firm ( firm $j$ ) is high. This is summed up in the fact that the cross derivative of the value function $\frac{\partial^{2} V_{i}}{\partial A_{i 1} \partial A_{j 1}}$ is negative. The sign taken by the interaction effect depends on the correlation between shocks which affect the return of projects of date 0 .

Proposition 2 For a given firm $j^{\prime}$ s hedging level $h_{j}$, the firm $i^{\prime}$ s hedging level is higher in the Aggregated Schocks Case than in the Independent Shocks Case which itself is higher than in the Perfectly Negatively Correlated Shocks Case, that is

$$
h_{i}^{\text {aggregated shocks }} \geq h_{i}^{\text {independent shocks }} \geq h_{i}^{\text {perfectly negatively correlated shocks }}
$$

\section{Proof. See appendix 4}

\subsubsection{Aggregated shocks}

Since shocks are aggregated ( $\rho=1)$, the firm $i$ 's date 1 amount of cash is high (low) when the firm $j$ 's date 1 amount of cash is also high (low). But, in the substitute case it is detrimental to firm $i$ when the firm $j^{\prime} s$ date 1 amount of cash is high. This means that when the firm $i^{\prime} s$ date 1 amount of cash is the lowest, its expected marginal value (what we will call its investment opportunities from now) is the highest. Firm $i$ 's date 1 amount of cash is perfectly negatively

\footnotetext{
${ }^{9}$ R emark about the production choice interpretation:

Traditionally in a Cournot game, the strategic variables are taken to be strategic substitutes, but there are cases where strategic variables are strategic complements (cf Bulow et al 1985).
} 
correlated with its investment opportunities. This effect tends to increase the hedging demand and explains why the interaction effect is positive.

This case turns out to be the one where the hedging demand is the highest.

\subsubsection{Independent shocks}

In that case, there is no particular link between the firms' date 1 amount of cash and their investment opportunities. This is why the interaction effect is equal to 0 .

Only the risk premium effect impacts the hedging demand.

\subsubsection{Perfectly negatively correlated shocks}

This case constitutes the opposite to the aggregated shocks case. When the firm $i^{\prime} s$ date 1 amount of cash is high, the firm $j^{\prime} s$ date 1 amount of cash is low. This means that the firm $i^{\prime} s$ date 1 amount of cash and its investment opportunities are perfectly correlated. This effect tends to lower the hedging demand and explains why the interaction effect is negative.

This case turns out to be the one where the hedging demand is the lowest.

\section{First results of comparative statics}

Suppose that firm $j$ is not subject to credit rationing. In that case, its hedging policy can result from others reasons like expected taxes or bankruptcy costs reduction. Such results of comparative statics are important since they indicate how some changes impact firm $i$ 's hedging policy which is driven by the problem of credit rationing, when firm $j$ 's hedging policy is driven by other reasons.

1. When the variance of the spot price $\sigma_{i}^{2}$ increases

Traditionally in the literature, the hedging demand is increasing with respect to the variance of the spot price $\widetilde{p}_{i}$, here $\sigma_{i}^{2}$ for firm $i$. Is it true in this model?

First, consider the direct effect of the variance $\sigma_{i}^{2}$ on firm $i^{\prime}$ s interaction effect. When $\sigma_{i}^{2}$ increases, firm $i$ 's interaction effect decreases in absolute value, except for $\rho=0$ since the interaction effect does not exist. Therefore, in the aggregated shocks case, this marginal effect is negative whereas it is positive in the perfectly negatively correlated shocks case. 
Finally, consider the effect of $\sigma_{i}^{2}$ on the risk premium effect. This effect corresponds to the traditional effect, often considered in the literature, of the variance on the hedging demand. The sign of this term is positive. When $\sigma_{i}^{2}$ increases this marginal effect tends to increase the hedging demand due to the concavity of the value function.

Therefore, the effect of $\sigma_{i}^{2}$ on $h_{i}$ is not clear. ${ }^{10}$ To sum up, consider the following board.

\begin{tabular}{|c|c|c|c|}
\hline & $\begin{array}{c}\text { Marginal effect } \\
\text { of } \sigma_{i}^{2} \text { on the firm i's } \\
\text { interaction effect }\end{array}$ & $\begin{array}{c}\text { M arginal effect of } \sigma_{i}^{2} \\
\text { on the firm i's risk } \\
\text { premium effect }\end{array}$ & $\begin{array}{c}\text { Global effect } \\
\text { of } \sigma_{i}^{2} \text { on } h_{i}\end{array}$ \\
\hline$\rho=1$ & $<0$ & $>0$ & $?$ \\
\hline$\rho=0$ & $=0$ & $>0$ & $>0$ \\
\hline$\rho=-1$ & $>0$ & $>0$ & $>0$ \\
\hline
\end{tabular}

2. When the firm $i$ 's date 0 amount of cash $A_{i 0}$ increases

When the firm $i$ 's date 0 amount of cash $A_{i 0}$ increases, the interaction effect is reduced in absolute value. When $A_{i 0}$ increases, $A_{i 1}$ increases on average. On average the firm $i$ 's investment opportunities decreases since the value function is concave in $A_{i 1}\left(\frac{\partial^{2} V_{i}}{\partial A_{i 1}^{2}}<0\right)$ which reduces the interaction effect.

When $A_{i 0}$ increases, the risk premium effect decreases in absolute value which increases the level of hedging. It becomes more and more costly in term of risk, not to hedge the return of the project of date $0 .{ }^{11}$

Finally, when shocks are independent or perfectly negatively correlated, the hedging demand increases. When shocks are aggregated, the interaction effect decreases which tend to reduce the hedging demand, but the risk premium effect increases which goes on the other direction.

\footnotetext{
${ }^{10}$ We can note that there is also an indirect effect of $\sigma_{i}^{2}$ on the firm i's interaction effect which corresponds to the indirect effect of $\sigma_{i}^{2}$ on $h_{j}$ times the effect of $h_{j}$ on $h_{i}$. We can proove, due to the computations of the following section, that it is negative when shocks are aggregated. It does not exist when they are independent and finally it can be negative or positive when they are perfectly negatively correlated.

${ }^{11}$ This result comes from the specification of the value function which is taken to be quadratic.
} 
3. When the firm $j$ 's date 0 amount of cash $A_{j 0}$ increases

When the date 0 amount of cash of the other firm $A_{j 0}$ increases, the interaction effect increases in absolute value. When $A_{j 0}$ increases, on average $A_{j 1}$ increases. Thus, on average the impact of firm $j$ on the firm $i$ 's investment opportunities increases.

Moreover, when $A_{j 0}$ increases the risk premium effect decreases in absolute value which increases the level of hedging. When $A_{j 0}$ increases, $A_{j 1}$ increases on average. Thus, the firm $i$ 's investment opportunities decrease on average $\left(\frac{\partial^{2} V_{i}}{\partial A_{i 1} \partial A_{j 1}}<0\right)$. Since the value function of firm $i$ is concave, he chooses to go to a safer position.

Therefore, when shocks are aggregated or independent, the chosen hedging level increases with $A_{j 0}$. But when shocks are perfectly negatively correlated, the interaction effect decreases which tend to reduce the hedging demand, but the risk premium effect increases which goes on the other direction.

4. When the private benefit $B$ of date 1 of the entrepreneur of firm $i$ increases

We have to remember that at the optimum, we have the following relation

$$
\frac{\partial V_{i}}{\partial A_{i 1}}=\frac{B}{\Delta P} \frac{\partial I_{i}}{\partial A_{i 1}}-1
$$

Therefore, the effect of the private benefit $B$ on the hedging demand corresponds only to the effect of $B$ on the risk premium effect. When the private benefit $B$ increases, the investment opportunities $\left(\frac{\partial V_{i}}{\partial A_{i 1}}\right)$ increases at the optimum (for example you can see that on the figure 1). Thus, when $B$ increases, it is more and more costly for the entrepreneur to hedge the return of the project of date 0 . Thus, when $B$ increases, the entrepreneur chooses a riskier position.

For a detailed proof of the four points, see appendix 5 . 


\subsection{The Symmetric Nash Equilibria}

B efore characterizing the symmetric Nash equilibria, we study the evolution of firm $i$ 's hedging demand with respect to the firm $j$ 's hedging level.

Lemma 2 For $\rho \in\{-1,0,1\}$ we have:

$$
\begin{aligned}
& \begin{array}{l}
\frac{\partial h_{i}\left(h_{j}\right)}{\partial h_{j}}\left(1+\frac{\left(\mathbb{E} \widetilde{p}_{i}-p\right)^{2}}{\sigma_{i}^{2}}\right)= \\
\underbrace{-\rho \frac{A_{j 0}}{A_{i 0}} \frac{\mathbb{E}\left(\frac{\partial^{2} V_{i}}{\partial A_{i 1} \partial A_{j 1}}\right)}{\mathbb{E}\left(\frac{\partial^{2} V_{i}}{\partial A_{i 1}^{2}}\right)} \frac{\sigma_{j}}{\sigma_{i}}-\frac{A_{j 0}}{A_{i 0}} \frac{\mathbb{E}\left(\frac{\partial^{2} V_{i}}{\partial A_{i 1} \partial A_{j 1}}\right)}{\mathbb{E}\left(\frac{\partial^{2} V_{i}}{\partial A_{i 1}}\right)} \frac{1}{\sigma_{i}} \frac{\left(\mathbb{E} \widetilde{p}_{i}-p\right)\left(\mathbb{E} \widetilde{p}_{j}-p\right)}{\sigma_{i}}}_{\text {term } 1}
\end{array} \underbrace{}_{\text {term } 2}
\end{aligned}
$$

\section{Proof. see appendix 6}

The expression of $\frac{\partial h_{i}}{\partial h_{j}}$ is composed of two terms. The first one represents the marginal interaction effect of the hedging demand function. The second term characterizes the marginal risk premium effect. The sign of these marginal effects depends on the sign of the cross derivative $\frac{\partial^{2} V_{i}}{\partial A_{i 1} \partial A_{j 1}}$, that is, on the nature of the interactions between firm $i$ and firm $j$.

Proposition 3 For the aggregated shocks case, the marginal interaction effect and the marginal risk premium effect have the same sign. This sign is negative. For the independent shocks case only the marginal risk premium effect exists. Thus, we have:

\section{$h_{i}$ is decreasing in $h_{j}$}

For the perfectly negatively correlated shocks case, the two marginal effects are opposite in sign. Thus, $h_{i}$ can be decreasing or increasing. More precisely we have:

$$
\begin{array}{|l|l|}
\hline \text { if }\left(\mathbb{E} \widetilde{p}_{i}-p\right)\left(\mathbb{E} \widetilde{p}_{j}-p\right)>-\operatorname{cov}\left(\widetilde{p}_{i}, \widetilde{p}_{j}\right) & h_{i} \text { is decreasing in } h_{j} \\
\hline \text { if }\left(\mathbb{E} \widetilde{p}_{i}-p\right)\left(\mathbb{E} \widetilde{p}_{j}-p\right)<-\operatorname{cov}\left(\widetilde{p}_{i}, \widetilde{p}_{j}\right) & h_{i} \text { is increasing in } h_{j} \\
\hline
\end{array}
$$

When $h_{j}$ increases, $A_{j 1}$ decreases on average. Thus, firm $i$ 's investment opportunities increase on average since we are in the substitute case. Thus, it becomes more and more costly for firm 
$i$ to hedge the return of its project of date 0 when $h_{j}$ increases. Note that this is all the more costly than the risk premium is high. Consequently, the risk premium effect (the speculative demand) decreases. The sign of the marginal risk premium effect is always negative.

The sign of the marginal interaction effect depends on which shocks we consider. When the shocks are aggregated, this marginal effect is negative. When firm $j$ 's hedging level increases, firm $i$ 's date 1 amount of cash and its investment opportunities become less and less negatively correlated. Thus, this marginal effect tends to decrease $h_{i}$.

When the shocks are independent, this marginal effect does not exist.

When the shocks are perfectly negatively correlated, this marginal effect is positive. In that case, when $h_{j}$ increases, firm $i$ 's date 1 amount of cash and its investment opportunities become less and less positively correlated. This marginal effect tends to increase $h_{i}$. Consequently, the overall impact when the shocks are perfectly negatively correlated depends on which marginal effect is greater. If the marginal risk premium effect is higher in absolute value (lower) than the marginal interaction effect, then the sign of $\frac{\partial h_{i}}{\partial h_{j}}$ is negative (positive).

For what follows we focus on the case of symmetric firms.

Assumption 1: $\left(\mathrm{A}_{1}\right)$ Firm $i$ and firm $j$ are symmetric if

$$
\begin{array}{|l|}
\hline A_{10}=A_{20} \\
\hline \sigma_{1}=\sigma_{2} \\
\hline \mathbb{E} \widetilde{p}_{1}=\mathbb{E} \widetilde{p}_{2} \\
\hline V_{1}\left(A_{11}, A_{21}\right)=V_{2}\left(A_{11}, A_{21}\right) \\
\hline
\end{array}
$$

Assumption 2: $\left(\mathrm{A}_{2}\right)$ We make the assumption that $\left|\mathbb{E}\left(\frac{\partial^{2} V_{i}}{\partial A_{i 1} \partial A_{j 1}}\right)\right|<\left|\mathbb{E}\left(\frac{\partial^{2} V_{i}}{\partial A_{i 1}^{2}}\right)\right|$

This second assumption corresponds to a stability condition as shown in remark 3 below. For reading convenience, let denote $h_{\rho}^{*}$ the equilibrium level of hedging for a correlation coefficient $\rho .^{12}$

Proposition 4 Under $A_{1}$ and $A_{2}$, there is an unique Nash equilibrium for each case. It is symmetric and stable. Moreover, if we compare the Nash equilibria we obtain the following

\footnotetext{
${ }^{12}$ Consequently, $h_{1}^{*}$ is the hedging equilibrium level for the aggregated shocks case. $h_{0}^{*}$ is the hedging equilibrium level for the independent shocks case. Finally, $h_{-1}^{*}$ is the hedging equilibrium level for the perfectly negatively correlated shocks case.
} 
ranking:

$$
h_{1}^{*}>h_{0}^{*}>h_{-1}^{*}
$$

That is, the level of hedging $h^{*}$ is increasing with the correlation coefficient of the shocks $\rho$.

Proof. We have:

- $\frac{\partial h_{i}}{\partial h_{j}} \leq 0$ for the aggregated and independent shocks cases.

- for the perfectly negatively correlated shocks case, $\frac{\partial h_{i}}{\partial h_{j}}$ could be negative or positive.

- $h_{i}^{\text {aggregated shocks }}(0)>h_{i}^{\text {independent shocks }}(0)>h_{i}^{\text {perfectly negatively correlated shocks }}(0)$

- $h_{i}^{\text {aggregated shocks }}(1)=h_{i}^{\text {independent shocks }}(1)=h_{i}^{\text {perfectly negatively correlated shocks }}(1)<1$

- the reaction functions are linear

We distinguish two cases:

First case: $\frac{\partial h_{i}}{\partial h_{j}} \leq 0 \forall \rho \in\{-1,0,1\}$

As shown in figure 2, the symmetric Nash equilibria are unique and respect proposition 4

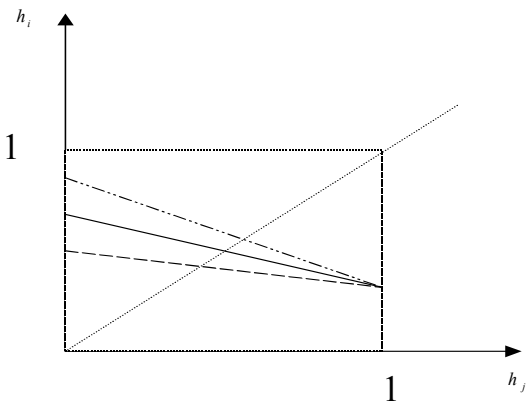

Figure 2

L e g end:

aggregated shocks case's reaction function independent shocks case's reaction function

perfectly inversely correlated shocks case's reaction function 
Second case: $\frac{\partial h_{i}}{\partial h_{j}} \leq 0$ for aggregated and independent shocks but $\frac{\partial h_{i}}{\partial h_{j}} \geq 0$ for perfectly negatively correlated shocks case.

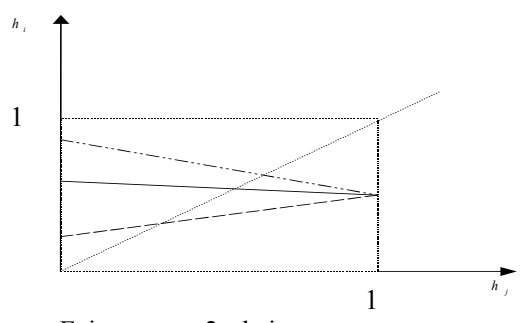

F ig u re 2 b is

As shown in figure 2 bis, the symmetric Nash equilibria are unique and respect proposition 4

Remark 3 When assumption 2 does not hold, there may exist several Nash equilibria in the game. The following details could be skipped in a first reading.

Consider first the aggregated shocks case. Without assumption 2 we could have multiplicity of Nash equilibria, as depicted in the following figure.

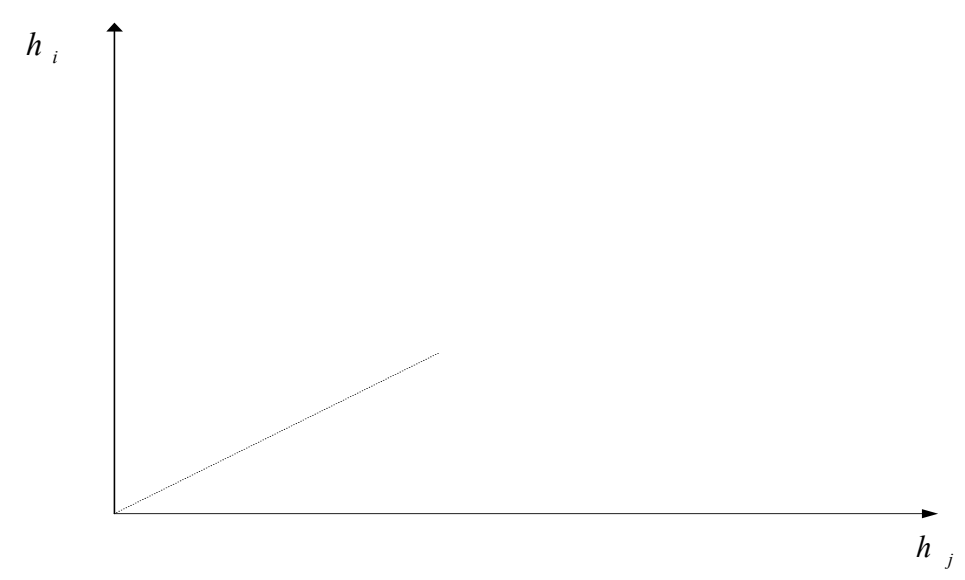


symmetric Nash equilibrium is not stable in a standard tatonnement process. ${ }^{13}$ There are two stable asymmetric equilibria in which one firm is fully hedged $\left(h_{i}=1\right)$. This case emerges for instance for a small risk premium but for a high interaction effect.

In all cases where $\frac{\partial h_{i}}{\partial h_{j}} \leq 0$, we could have several Nash equilibria as depicted in the figure just below. There are two stable asymmetric equilibria in which one firm is not hedged at all $\left(h_{i}=0\right)$. This case emerges for very high risk premiums. Here again, the symmetric Nash equilibrium is not stable.

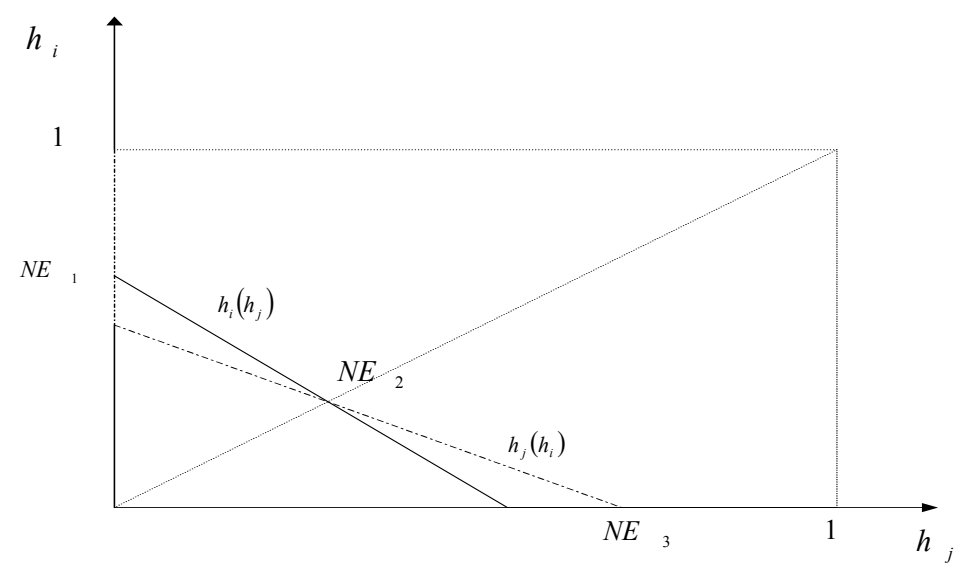

Thus, for all these cases assumption 2 which permits the symmetric Nash equilibrium to be the unique Nash equilibrium, corresponds to a stability condition.

Finally, consider the perfectly negatively correlated shocks case, when $\frac{\partial h_{i}}{\partial h_{j}} \geq 0$. In that case, there is always a unique symmetric Nash equilibrium (remember that $h_{-1}(0)<1$ ), which may correspond to no hedging at all, if the risk premium is very high.

The ranking of the different hedging levels is still the same at the equilibrium. This comes from the fact that, at the equilibrium, the hedging levels are not equal to one because of the risk premium. Thus, the interaction effect exists and it implies this ranking. Following the

\footnotetext{
${ }^{13}$ Definition of a standard tatonnement process: for a slight exogenous increase in $h_{i}$, we compute the change it induces in the equilibrium best response of firm $j$, that is, in the partial equilibrium of firm $j$ taking the new hedging level of firm $i$ as given. Then, we compute firm $i$ 's own best response. If this best response is not closer than the exogenous initial disturbance to the equilibrium value, the equilibrium is not stable. On the other hand, if this best response is closer than the exogenous initial change to the equilibrium value, the equilibrium is stable.
} 
terminology of Froot et al (1993), we could speak of changing investment opportunities to explain the differences between the optimal hedging strategies. Our results corroborate their results, but we endogenized the changing investment opportunities in terms of interactions between firms. Moreover, we went one step further by going to the Nash equilibrium.

We now study the impact of various changes in the environment on the characteristics of the Nash equilibria.

\subsubsection{Increasing the risk premium (for symmetric firms)}

Consider first the impact of an increase in the risk premium $(\mathbb{E} \widetilde{p}-p)$, when the value function $V_{i}$ does not change.

By using the implicit function theorem, we have:

$$
\frac{d h_{i}}{d(\mathbb{E} \widetilde{p}-p)}=\frac{\frac{1}{\sigma^{2}}\left[\mathbb{E} \frac{\partial V_{i}}{\partial A_{i 1}} \frac{1}{A_{i 0}}-h_{i}\left(\frac{\partial^{2} V_{i}}{\partial A_{i 1}^{2}}+\frac{\partial^{2} V_{i}}{\partial A_{i 1} \partial A_{j 1}}\right)(\mathbb{E} \widetilde{p}-p)\right]}{\left[\mathbb{E} \frac{\partial^{2} V_{i}}{\partial A_{i 1}^{2}}\left(1+\frac{(\mathbb{E} \widetilde{p}-p)^{2}}{\sigma_{i}^{2}}\right)+\mathbb{E} \frac{\partial^{2} V_{i}}{\partial A_{i 1} \partial A_{j 1}}\left(\rho+\frac{(\mathbb{E} \widetilde{p}-p)^{2}}{\sigma_{i}^{2}}\right)\right]}<0
$$

Thus, the hedging demand clearly decreases when the risk premium increases. This effect is unambiguous. If the risk premium increases and the value function $V_{i}$ stays the same, the trade-off between the two goes toward a riskier position.

\subsubsection{Increasing the interactions between firms}

Consider finally an increase in the interactions between firms. That means increasing $\frac{\partial^{2} V_{i}}{\partial A_{i 1} \partial A_{j 1}}$ while keeping $\frac{\partial^{2} V_{i}}{\partial A_{i 1}^{2}}$ constant. Here too, this effect is unambiguous. If $\frac{\partial^{2} V_{i}}{\partial A_{i 1} \partial A_{j 1}}$ increases and $\frac{\partial^{2} V_{i}}{\partial A_{i 1}^{2}}$ is constant, the interaction effect of firm $i$ 's hedging demand increases in absolute value. Thus, firm $i$ 's reaction function shifts upward for the aggregated shocks case and downward for the perfectly negatively correlated shocks case. For the independent shocks case, firm $i$ 's reaction function does not change since the first term we are talking about does not then exist. 
The changes are described in the following figures
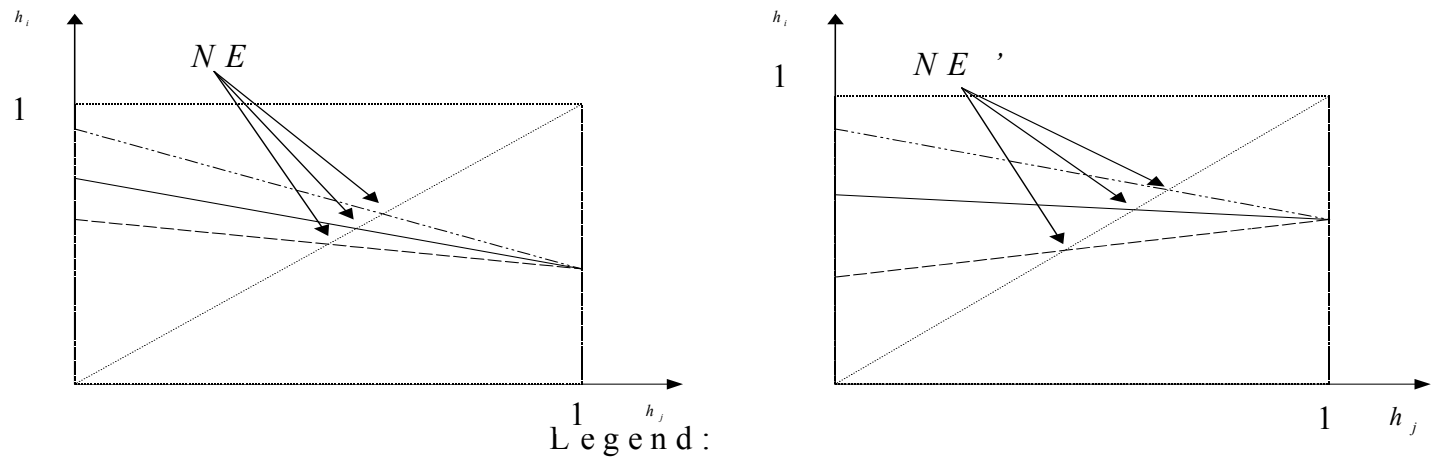

aggregated shocks case's reaction function

independent shocks case's reaction function

perfectly inversely correlated shocks case's reaction function

Consequently, for a given risk premium level, the higher are the interactions between firms, the higher are the differences between the equilibrium hedging levels.

\section{Complementary section: the complement case}

This section follows the study done above for the other case we are interested in, that is, for the complement case. Here, we consider that the cross derivative $\frac{\partial^{2} V_{i}}{\partial A_{i 1} \partial A_{j 1}}$ is positive. This means that it is beneficial for firm $i$ when firm $j^{\prime} s$ date 1 amount of cash is high. Firm $i$ 's marginal value is increasing with respect to firm $j$ 's date 1 amount of cash. Consequently, the sign of the interaction effect defined in lemma 1 is the opposite of the sign obtained for the substitute case. In the aggregated shocks case this sign is negative and in the perfectly negatively correlated shocks case it is positive. As before, in the independent shocks case this term does not exist. Thus, the results corresponding to this case are reversed with respect to the substitute case.

Proposition 5 For a given firm $j^{\prime} s$ hedging level $h_{j}$, the firm $i^{\prime} s$ hedging level is higher in the Perfectly Negatively Correlated Shocks Case than in the Independent Shocks Case which itself is higher than in the Aggregated Shocks Case, that is

$$
h_{i}^{\text {aggregated shocks }} \leq h_{i}^{\text {independent shocks }} \leq h_{i}^{\text {perfectly negatively correlated shocks }}
$$


Proof. We follow exactly the same method as for the proof of proposition 2, but the result is reversed because the sign of the cross derivative is positive and not negative.

Firm i's hedging demand is the lowest in the aggregated shocks case because its date 1 amount of cash is perfectly correlated with its investment opportunities. Conversely, firm $i$ 's hedging demand is the highest in the perfectly negatively correlated shocks case because then, its date 1 amount of cash is perfectly negatively correlated with its investment opportunities.

\section{R esults of comparative statics}

1. When the variance of the spot price $\sigma_{i}^{2}$ increases

The marginal effect of $\sigma_{i}^{2}$ on the risk premium effect is still the same. M oreover, when $\sigma_{i}^{2}$ increases, firm $i$ 's interaction effect also still decreases in absolute value. In the complement case, this means that in the aggregated shocks case the direct marginal effect of $\sigma_{i}^{2}$ on firm $i^{\prime}$ s interaction effect is positive, while for the perfectly negatively correlated shocks it is negative. In the complement case, the effect of $\sigma_{i}^{2}$ on $h_{i}$ is not clear when shocks are perfectly negatively correlated.

2. When the firm $i$ 's date 0 amount of cash $A_{i 0}$ increases

On the one hand, when the firm $j^{\prime}$ s date 0 amount of cash $A_{j 0}$ increases, the interaction effect decreases in absolute value. This tends to increase the hedging demand in the aggregated shocks case and to decrease it in the perfectly negatively correlated shocks case.

On the other hand, the effect of $A_{j 0}$ on the risk premium effect is still the same. This effect decreases in absolute value which increases the level of hedging.

The effect of an increase of $A_{i 0}$ on $h_{i}$ is also not clear in the perfectly negatively correlated shocks case. 
3. When the firm $j$ 's date 0 amount of cash $A_{j 0}$ increases

On the one hand, when the firm $j^{\prime}$ s date 0 amount of cash $A_{j 0}$ increases, the interaction effect increases in absolute value. This tends to decrease the hedging demand in the aggregated shocks case and to increase it in the perfectly negatively correlated shocks case. On the other hand, when $A_{j 0}$ increases, the risk premium effect increases in absolute value which decreases the level of hedging. When $A_{j 0}$ increases, $A_{j 1}$ increases on average. Thus, on average the firm $i$ 's investment opportunities increases. Thus, it is more and more costly for firm $i$ to hedge the return of its project of date 0 .

Therefore, the effect of an increase of $A_{j 0}$ on $h_{i}$ is once again not clear in the perfectly negatively correlated shocks case.

The analysis with respect to the private benefit $B$ is exactly the same as in the substitute case.

For more details, see appendix 5. 


\subsection{The Symmetric Nash Equilibria}

Lemma 2 tells us that the signs of the slopes of firm $i$ 's reaction functions are reversed in the complement case with respect to the substitute case. The demonstrations are also reversed.

Proposition 6 For the aggregated shocks case, the marginal interaction effect and the marginal risk premium effect are both positive. For the independent shocks case only the risk premium effect exists. Thus, we have:

\section{$h_{i}$ is increasing in $h_{j}$}

For the perfectly negatively correlated shocks case, the two marginal effects are opposite in sign. Thus, $h_{i}$ can be decreasing or increasing. More precisely we have:

\begin{tabular}{|l|l|}
\hline if $\left(\mathbb{E} \widetilde{p}_{i}-p\right)\left(\mathbb{E} \widetilde{p}_{j}-p\right)>-\operatorname{cov}\left(\widetilde{p}_{i}, \widetilde{p}_{j}\right)$ & $h_{i}$ is increasing in $h_{j}$ \\
\hline if $\left(\mathbb{E} \widetilde{p}_{i}-p\right)\left(\mathbb{E} \widetilde{p}_{j}-p\right)<-\operatorname{cov}\left(\widetilde{p}_{i}, \widetilde{p}_{j}\right)$ & $h_{i}$ is decreasing in $h_{j}$ \\
\hline
\end{tabular}

This proposition is illustrated in the following two figures:

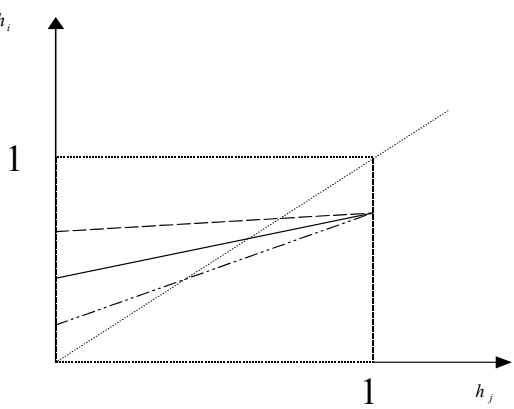

Figure 3 a

The complement

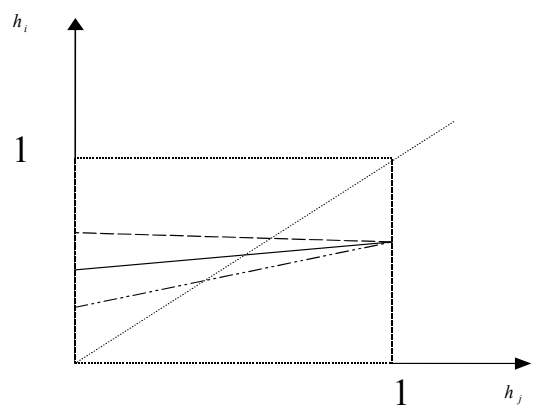

Figure $3 b$ case

Legend:

aggregated shocks case's reaction function independent shocks case's reaction function perfectly inversely correlated shocks case's reaction function 
Proposition 7 Under $A_{1}$ and $A_{2}$, there is an unique Nash equilibrium for each case. It is symmetric and stable. Moreover, if we compare the Nash equilibria, we obtain the following ranking:

$$
h_{1}^{*}<h_{0}^{*}<h_{-1}^{*}
$$

That is, the level of hedging $h^{*}$ is decreasing with the correlation coefficient of the shocks $\rho$.

Proof. The demonstration follows step by step the demonstration of proposition 4. For the details see appendix 7 .

As above, the same remark concerning the role of assumption 2 could be made for this case.

As in the first case we can do comparative statics. The results are the same as in the first case:

1. If the risk premium increases, the entrepreneurs choose lower hedging levels.

2. Besides, for a given risk premium level, the higher are the interactions between firms, the higher are the differences between the equilibrium hedging levels.

\section{Link with the hedging literature and conclusion}

\subsection{Link with the hedging literature}

First of all, according to the Modigliani-M iller paradigm, we know that hedging activities do not change the firm's value. In the Arrow-D ebreu model, the corner stone of modern finance, capital structure is irrelevant, as cited in Holmström-Tirole 1999. A ny theory of corporate finance must be grounded in some deviation from the assumed completeness of markets and the absence of cost of financial distress and taxes.

Following M ayers and Smith (1982), several explanations for hedging demand by corporations have been put forward. One explanation is based on fiscal considerations. W ith a convex tax schedule, J ensen's inequality implies that expected taxes are reduced by hedging. The more convex the effective tax schedule, the greater is the reduction in expected taxes. Statutory 
progressivity, a common feature of systems, can cause convexity in the tax schedule. Smith and Stulz (1985) make a similar argument.

Mac-M inn (1987) considers a model with costly bankruptcy. He argues that hedging reduces the probability of the firm suffering financial distress by lowering the variance of firm value. He then shows that hedging can eliminate or reduces bankruptcy costs in a argument similar to Mayers and Smith (1982) and Smith and Stulz (1985). But in those models bankruptcy costs and debt are exogenous. Caillaud, Dionne and J ullien (2000) address this issue using an extension of Gale and Hellwig (1985). They consider two independent sources of risks that affect the firm's return. They put their model in the costly state verification paradigm, that is, the outcome of the risks is not costlessly observable by the lender. In such a framework, they derive the optimal contract which can be decomposed into a bundle of a debt contract and an insurance contract with franchise. The optimal contract trades-off between the two costly sources of audit.

Froot, Scharfstein and Stein (1993) consider that external sources of finance are more costly than internal sources because capital markets are imperfect. They argue that hedging activity shifts internal funds from excess cash states toward deficit states. In their model, hedging is viewed as an instrument for coordinating corporate investment and financing policies. This paper is the closest to our own. Our results follow their, but we endogenize the capital market imperfections and what they call the investment opportunities. A paper in the same direction is Holmström and Tirole (1999). Their capital market imperfection is related to asymmetric information. A firm cannot pledge the entire net present value of its project to new investors. They show that firms should be isolated from all shocks that can be costlessly hedged in capital markets in order to reduce the variability in investment rules.

A different line of research looks at issues related to agency costs within the firm. Stockholders of a firm may have incentives to reject a positive net present value project if the benefits of the project go to the bondholders. Hence, realizing that stockholders can behave opportunistically, bondholders can protect themselves by lowering their offer price. Moreover, problem of "debt overhang" à la Myers (1977) can exist. Mac-Minn (1987) shows how hedging or insurance can eliminate or reduce such agency problems. A similar line is taken in M ac-M inn and $\mathrm{Han}$ (1990) 
and M ayers and Smith (1987). These motivations are not taken into consideration in this paper.

More recently, Grace and Rebello (1993) and Rebello (1995) studied a situation in which firms have private information on its expected cash-flows and on its expected losses. They also assume that firms with high operating revenues also face high insurable risks. In such a context, hedging or insurance is viewed as a signal about the quality of the firm. Favorable information is revealed by the purchase of high coverage.

\subsection{Concluding remarks}

In a situation where there is credit rationing, we have analyzed firms' optimal hedging strategies. We showed how hedging demand depends on the nature of interactions between firms and on the correlation between shocks affecting firms' internal funds. This give us testable implications. Knowing the nature of the interactions between firms, we could test if the hedging demand increases or decreases when we go from the aggregated shocks case to the perfectly negatively correlated shocks case. More precisely, in the case of strategic substitutes, it could be possible to empirically test the theoretical results on some raw material market very concentrated (petrol, nickel, ...), for which firms' hedging demand can be correctly estimated by the size of their off balance sheet positions.

A nother question could be to know whether our results are still valid in other types of competition between firms. In an oligopolistic case, firms' interactions could change but still exist. Thus, our results should be robust to this case.

In a competitive case, interactions between each firm tend to disappear. In this situation, what matters should be the correlation between the amount of cash of one firm and the average amount of cash of all other firms rather than the correlation between the amount of cash of one firm and the amount of cash of another particular firm. It is, however, the scope of future research to clarify these questions.

Finally, let us give two topics of future research which could generate a hedging demand for a risk neutral entrepreneur. Taking into account the possibility of predation would lead a firm to hedge against low income. Consider a situation where there are two firms on a market and their products are substitutes. There is a rich incubent and an indebted entrant. If the entrant's 
result is below a precise threshold, the entrant is liquidated. This context is favorable to an incubent's predation behavior which tries to eject the entrant out of the market. To avoid a too aggressive incumbent behavior, and under the assumption that hedging contracts are observable, even a risk neutral entrant can choose to hedge its result to avoid such predatory behavior.

Along another line, we could consider how mergers and acquisitions modify the nature of investment opportunities. The resale price of a firm depends on whether or not there are buyers standing by ready to purchase the firm. This depends on the extent to which other firms that could be potential candidates to purchase the firm have accumulated the knowledge necessary to manage the firm and have enough money to buy it. In a context of very specialized firms, when there is an adverse aggregated shock at the level of the industry, the resale price of a firm inside this industry will be very low. Indeed, the firms which have the necessary knowledge, that is, firms in the same industry are then very poor. Therefore, if a firm has to be liquidated, its resale price would be very low in this situation (cf: Shleifer and Vishny 1992). In such a context, firms have an incentive to hedge their results against adverse aggregated shocks for two reasons. First, to be able to buy at a low price another firm of the same industry which has to be liquidated. Second, to avoid being liquidated at a very low price. In this context, we guess that the more a firm hedges its result, the less other firms will hedge theirs. 


\section{References}

[1] J. Bulow, J . Geanakoplos, P. K lemperer (1985): Multimarket Oligopoly: Strategic Substitutes and Complements, Journal of Political Economy

[2] B. Caillaud, G. Dionne, B. J ullien (2000): Corporate Insurance with Optimal Financial Contracting, Economic Theory

[3] A. Faure-Grimaud (1998): Structure Financière et Concurrence Imparfaite : ModiglianiMiller 40 ans après, Revue d'Economie Politique

[4] K A. Froot, D S.Scharfstein-J C. Stein: Risk Management (1993): Coordinating Corporate Investment and Financing Policies, The Journal of Finance

[5] D. Fudenberg, J . Tirole (1984): The Fat-Cat Effect, The Puppy-Dog Ploy and the Lean and Hungry Look, American Economic Review

[6] C. Géczy, B. A. M inton and C. Schrand (1997): W hy Firms Use Currency Derivatives, The Journal of Finance, vol LII, Nb04

[7] D. Gale, M. Hellwig (1985): Incentives Compatible Debt Contracts: the one period problem, Revue of Economics Studies

[8] M.F. Grace, M .J . Rebello (1993): Financing and the Demand for Corporate Insurance, The Geneva Papers on Risk and Insurance Theory

[9] Holmström, B. et J . Tirole (1998b) : Private and Public Supply of Liquidity, Journal of Political Economy, 106: 1-40

[10] Holmström, B. et J. Tirole (1999) : Liquidity and Risk Management, Journal of Money, Credit and Banking lecture, delivered on A pril 16, 1999 at Ohio State University

[11] R. Mac-M inn (1987): Insurance and Corporate Risk Management, Journal of Risk and Insurance 
[12] R. Mac-Minn, L. Han (1990): Limited Liability, Corporate Value and The Demand for Liability Insurance, Journal of Risk and Insurance

[13] D. Mayers, C.W. Smith (1982): On the Corporate Demand for Insurance, Journal of Business

[14] D. Mayers, C.W. Smith (1987): Corporate Insurance and the Underinvestment Problem, The Journal of Risk and Insurance

[15] F. Modigliani, M.H. Miller (1958): The Cost of Capital, Corporation Finance and The Theory of Investment, American Economic Review

[16] S. Myers (1977): Determinants of Corporate Borrowing, Journal of Financial Economics

[17] D. Nance, C. Smith, C. Smithson (1993): On the Determinants of Corporate Hedging, The Journal of Finance

[18] M.J. Rebello (1995): Adverse Selection Costs and the Firm's Financing and Insurance Decisions, Journal of Financial Intermediation

[19] M. Rubinstein (1976): The Valuation of Uncertain Income Streams and the Pricing of Options, The Journal of Finance

[20] A. Shleifer, R. Vishny (1992): Liquidation Values and Debt Capacity: a market equilibrium approach, The Journal of Finance

[21] C. W. Smith, R. M. Stulz (1985): The Determinants of Firm's Hedging Policies, Journal of Quantitative Analysis

[22] J. Tirole (1996): Lecture Notes on Corporate Finance, Université de Toulouse 


\section{Appendix 1: study of the function $\pi_{i}\left(I_{i}, I_{j}\right)-I_{i}$}

We have to check that the function $V_{i}=\pi_{i}\left(I_{i}, I_{j}\right)-I_{i}$ with $I_{i}, I_{j}$ defined by the two implicit functions

$$
\left\{\begin{array}{c}
\pi_{i}\left(I_{i}, I_{j}\right)-I_{i}=\frac{B I_{i}}{\Delta p}-A_{i 1} \\
\pi_{j}\left(I_{j}, I_{i}\right)-I_{j}=\frac{B I_{j}}{\Delta p}-A_{j 1}
\end{array}\right.
$$

is increasing, concave in $A_{i 1}$ and that the cross derivative is negative when $I_{i}, I_{j}$ are strategic substitutes and positive when $I_{i}, I_{j}$ are strategic complements. ${ }^{14}$ We denote $\pi_{i}\left(I_{i}, I_{j}\right)$ by $\pi_{i}$ and $\pi_{j}\left(I_{i}, I_{j}\right)$ by $\pi_{j}$, to simplify the notations.

$$
\frac{\partial V_{i}}{\partial A_{i 1}}=\underbrace{\left(\frac{\partial \pi_{i}}{\partial I_{i}}-1\right)}_{>0 \text { by hypothesis }} \frac{\partial I_{i}}{\partial A_{i 1}}+\frac{\partial \pi_{i}}{\partial I_{j}} \frac{\partial I_{j}}{\partial A_{i 1}}
$$

We determine the sign of $\frac{\partial I_{i}}{\partial A_{i 1}}$. We differentiate and resolve the system of the two implicit equations.

$$
\left\{\begin{array}{c}
\frac{\partial \pi_{i}}{\partial I_{i}} \frac{\partial I_{i}}{\partial A_{i 1}}+\frac{\partial \pi_{i}}{\partial I_{j}} \frac{\partial I_{j}}{\partial A_{i 1}}-\frac{\partial I_{i}}{\partial A_{i 1}}-\frac{B}{\Delta p} \frac{\partial I_{i}}{\partial A_{i 1}}+1=0 \\
\frac{\partial \pi_{j}}{\partial I_{i}} \frac{\partial I_{i}}{\partial A_{i 1}}+\left[\frac{\partial \pi_{j}}{\partial I_{j}}-1-\frac{B}{\Delta p}\right] \frac{\partial I_{j}}{\partial A_{i 1}}=0
\end{array}\right.
$$

By resolving for $\frac{\partial I_{j}}{\partial A_{i 1}}=\frac{\frac{\partial \pi_{j}}{\partial I_{i}} \frac{\partial I_{i}}{\partial A_{i 1}}}{1+\frac{B}{\Delta p}-\frac{\partial \pi_{j}}{\partial I_{j}}}$ we have:

$$
\frac{\partial I_{i}}{\partial A_{i 1}}=\frac{1+\frac{B}{\Delta p}-\frac{\partial \pi_{j}}{\partial I_{j}}}{\left(1+\frac{B}{\Delta p}-\frac{\partial \pi_{i}}{\partial I_{i}}\right)\left(1+\frac{B}{\Delta p}-\frac{\partial \pi_{j}}{\partial I_{j}}\right)-\frac{\partial \pi_{i}}{\partial I_{j}} \frac{\partial \pi_{j}}{\partial I_{i}}}
$$

The numerator is denoted $N$, the denominator $D$.

We suppose that the first cross derivatives of the two profit functions, $\frac{\partial \pi_{i}}{\partial I_{j}}$ and $\frac{\partial \pi_{j}}{\partial I_{i}}$, are small. $1+\frac{B}{\Delta p}-\frac{\partial \pi_{i}}{\partial I_{i}}$ and $1+\frac{B}{\Delta p}-\frac{\partial \pi_{j}}{\partial I_{j}}$ are positive (cf: figure 1). Thus, $\frac{\partial I_{i}}{\partial A_{i 1}}$ is positive.

\footnotetext{
${ }^{14}$ When $I_{i}, I_{j}$ are strategic substitutes, we have, $\frac{\partial^{2} \pi\left(I_{i}, I_{j}\right)}{\partial I_{i} \partial I_{j}}<0$

When $I_{i}, I_{j}$ are strategic complements, we have, $\frac{\partial^{2} \pi\left(I_{i}, I_{j}\right)}{\partial I_{i} \partial I_{j}}>0$
} 
The sign of $\frac{\partial I_{j}}{\partial A_{i 1}}$ corresponds to the sign of $\frac{\partial \pi_{j}}{\partial I_{i}}$. Thus, the sign of $\frac{\partial \pi_{i}}{\partial I_{j}} \frac{\partial I_{j}}{\partial A_{i 1}}$ corresponds to the sign of $\frac{\partial \pi_{i}}{\partial I_{j}} \frac{\partial \pi_{j}}{\partial I_{i}}$, which is positive. Indeed, $\frac{\partial \pi_{i}}{\partial I_{j}}$ and $\frac{\partial \pi_{j}}{\partial I_{i}}$ have the same sign since the effect of $I_{j}$ on $\pi_{i}$ and the effect of $I_{i}$ on $\pi_{j}$, are the same.

Therefore, $V_{i}$ is increasing in $A_{i 1}\left(\frac{\partial V_{i}}{\partial A_{i 1}} \geq 0\right)$.

Since at the optimum, $\pi_{i}\left(I_{i}, I_{j}\right)-I_{i}=\frac{B I_{i}}{\Delta p}-A_{i 1}$ we have:

$$
\frac{\partial^{2} V_{i}}{\partial A_{i 1}^{2}}=\frac{B}{\Delta p} \frac{\partial^{2} I_{i}}{\partial A_{i 1}^{2}}
$$

The sign of this expression corresponds to the sign of $\frac{\partial^{2} I_{i}}{\partial A_{i 1}^{2}}$

$$
\begin{aligned}
& \frac{\partial^{2} I_{i}}{\partial A_{i 1}^{2}}=\frac{1}{D^{2}}\left\{\begin{array}{c}
\frac{\partial^{2} \pi_{j}}{\partial I_{j} \partial I_{i}}\left(-D+\left(1+\frac{B}{\Delta p}-\frac{\partial \pi_{i}}{\partial I_{i}}\right) N\right)+N \frac{\partial^{2} \pi_{i}}{\partial I_{i}^{2}}\left(1+\frac{B}{\Delta p}-\frac{\partial \pi_{j}}{\partial I_{j}}\right) \\
+N \frac{\partial^{2} \pi_{i}}{\partial I_{j} \partial I_{i}} \frac{\partial \pi_{j}}{\partial I_{i}}+N \frac{\partial \pi_{i}}{\partial I_{j}} \frac{\partial^{2} \pi_{j}}{\partial I_{i}^{2}}
\end{array}\right] \frac{\partial I_{i}}{\partial A_{i 1}} \\
& \left.+\left[\begin{array}{c}
\frac{\partial^{2} \pi_{j}}{\partial I_{j}^{2}}\left(-D+\left(1+\frac{B}{\Delta p}-\frac{\partial \pi_{i}}{\partial I_{i}}\right) N\right)+N \frac{\partial^{2} \pi_{i}}{\partial I_{j} \partial I_{i}}\left(1+\frac{B}{\Delta p}-\frac{\partial \pi_{j}}{\partial I_{j}}\right) \\
+N \frac{\partial^{2} \pi_{i}}{\partial I_{j}^{2}} \frac{\partial \pi_{j}}{\partial I_{i}}+N \frac{\partial \pi_{i}}{\partial I_{j}} \frac{\partial^{2} \pi_{j}}{\partial I_{j} \partial I_{i}}
\end{array}\right] \frac{\partial I_{j}}{\partial A_{i 1}}\right\}
\end{aligned}
$$

For $\frac{\partial^{2} \pi_{j}}{\partial I_{j} \partial I_{i}}, \frac{\partial^{2} \pi_{i}}{\partial I_{j}^{2}}, \frac{\partial^{2} \pi_{i}}{\partial I_{j} \partial I_{i}}, \frac{\partial^{2} \pi_{j}}{\partial I_{j}^{2}}, \frac{\partial^{2} \pi_{j}}{\partial I_{i}^{2}}$ bounded and $\frac{\partial \pi_{j}}{\partial I_{i}}, \frac{\partial \pi_{i}}{\partial I_{j}}$ small enough, the sign of this expression corresponds to the sign of

$$
\begin{aligned}
& \frac{\partial^{2} \pi_{j}}{\partial I_{j} \partial I_{i}}\left(\begin{array}{c}
-D+\left(1+\frac{B}{\Delta p}-\frac{\partial \pi_{i}}{\partial I_{i}}\right) N \\
=\frac{\partial \pi_{i}}{\partial I_{j}} \frac{\partial \pi_{j}}{\partial I_{i}} \text { small }
\end{array}\right)+N \frac{\partial^{2} \pi_{i}}{\partial I_{i}^{2}}\left(1+\frac{B}{\Delta p}-\frac{\partial \pi_{j}}{\partial I_{j}}\right) \\
& \Longleftrightarrow N \frac{\partial^{2} \pi_{i}}{\partial I_{i}^{2}}\left(1+\frac{B}{\Delta p}-\frac{\partial \pi_{j}}{\partial I_{j}}\right)^{2} \leq 0
\end{aligned}
$$

The sign of $\frac{\partial^{2} I_{i}}{\partial A_{i 1}^{2}}$ and the sign of $\frac{\partial^{2} \pi_{i}}{\partial I_{i}^{2}}$ are the same. Consequently, $\frac{\partial^{2} I_{i}}{\partial A_{i 1}^{2}}$ is negative. Thus, $\frac{\partial^{2} V_{i}}{\partial A_{i 1}^{2}}$ is negative. 


$$
\frac{\partial^{2} V_{i}}{\partial A_{i 1} \partial A_{j 1}}=\frac{B}{\Delta p} \frac{\partial^{2} I_{i}}{\partial A_{i 1} \partial A_{j 1}}
$$

The sign of this expression corresponds to the sign of $\frac{\partial^{2} I_{i}}{\partial A_{i 1} \partial A_{j 1}}$

$$
\begin{aligned}
& \frac{\partial^{2} I_{i}}{\partial A_{i 1} \partial A_{j 1}}= \\
& \frac{1}{D^{2}}\left\{\left[\begin{array}{c}
\left(\begin{array}{c}
-D+N\left(1+\frac{B}{\Delta p}-\frac{\partial \pi_{i}}{\partial I_{i}}\right) \\
=\frac{\partial \pi_{i}}{\partial I_{j}} \frac{\partial \pi_{j}}{\partial I_{i}}
\end{array}\right) \frac{\partial^{2} \pi_{j}}{\partial I_{j}^{2}}+N \frac{\partial^{2} \pi_{i}}{\partial I_{j} \partial I_{i}}\left(1+\frac{B}{\Delta p}-\frac{\partial \pi_{j}}{\partial I_{j}}\right) \\
+N \frac{\partial^{2} \pi_{i}}{\partial I_{j}^{2}} \frac{\partial \pi_{j}}{\partial I_{i}}+N \frac{\partial \pi_{i}}{\partial I_{j}} \frac{\partial^{2} \pi_{j}}{\partial I_{j} \partial I_{i}}
\end{array}\right] \frac{\partial I_{j}}{\partial A_{j 1}}\right.
\end{aligned}
$$

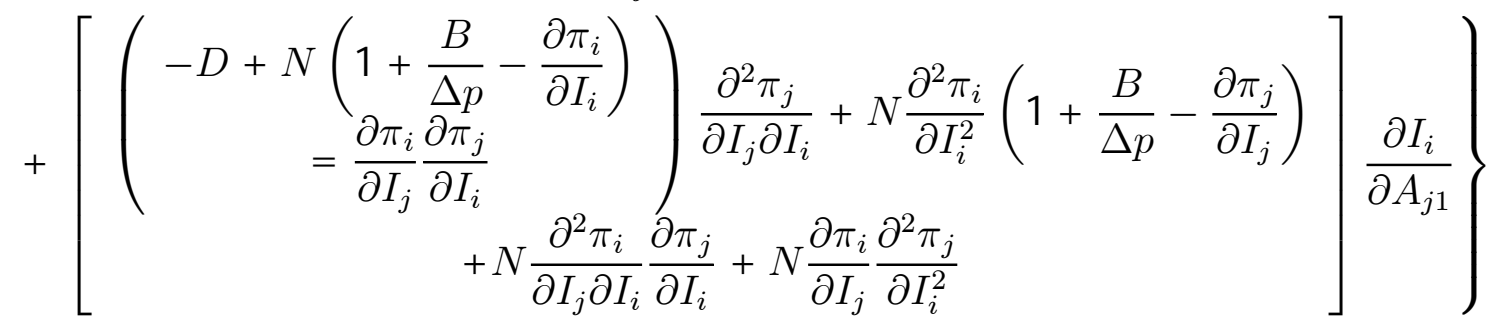

For $\frac{\partial^{2} \pi_{j}}{\partial I_{j} \partial I_{i}}, \frac{\partial^{2} \pi_{i}}{\partial I_{j}^{2}}, \frac{\partial^{2} \pi_{i}}{\partial I_{j} \partial I_{i}}, \frac{\partial^{2} \pi_{j}}{\partial I_{j}^{2}}, \frac{\partial^{2} \pi_{j}}{\partial I_{i}^{2}}$ bounded and $\frac{\partial \pi_{j}}{\partial I_{i}}, \frac{\partial \pi_{i}}{\partial I_{j}}$ small enough, the sign of this expression is given by the sign of

$$
\underbrace{N\left(1+\frac{B}{\Delta p}-\frac{\partial \pi_{j}}{\partial I_{j}}\right)}_{\geq 0} \frac{\partial^{2} \pi_{i}}{\partial I_{j} \partial I_{i}} \underbrace{\frac{\partial I_{j}}{\partial A_{j 1}}}_{\geq 0}
$$

In the strategic substitutes case, $\frac{\partial^{2} \pi_{i}}{\partial I_{j} \partial I_{i}}$ is negative. $\frac{\partial^{2} I_{i}}{\partial A_{i 1} \partial A_{j 1}}$ is then negative as $\frac{\partial^{2} V_{i}}{\partial A_{i 1} \partial A_{j 1}}$.

In the strategic complements case, $\frac{\partial^{2} \pi_{i}}{\partial I_{j} \partial I_{i}}$ is positive. $\frac{\partial^{2} I_{i}}{\partial A_{i 1} \partial A_{j 1}}$ is then positive as $\frac{\partial^{2} V_{i}}{\partial A_{i 1} \partial A_{j 1}}$ Consequently, the function $V_{i}=\pi_{i}\left(I_{i}, I_{j}\right)-I_{i}$ with $I_{i}, I_{j}$ defined by the system of two implicit functions has the desired properties. 


\section{Appendix 2: optimal hedging level}

First of all, we are going to establish a useful lemma which we will use to obtain the optimal hedging demand functions.

Lemma 3 Let $(x, y)$ be a couple of random variables distributed according to a Bivariate Normal law, with respective variance $\sigma_{x}^{2}, \sigma_{y}^{2}$ and correlation coefficient $\rho$.

Let $b(x, y): I R^{2} \rightarrow I R$ continuously differentiable.

Then, for $\rho \in\{-1,0,1\}$ we have:

$$
\operatorname{cov}(x ; b(x, y))=\mathbb{E}\left[\frac{\partial b(x, y)}{\partial x}+\rho \frac{\sigma_{y}}{\sigma_{x}} \frac{\partial b(x, y)}{\partial y}\right] \sigma_{x}^{2}
$$

Proof. The Rubinstein (1976) rule is the following:

Let $(x, y)$ be a couple of random variables distributed according to a Bivariate Normal law, with respective variance $\sigma_{x}^{2}, \sigma_{y}^{2}$ and correlation coefficient $\rho$.

Let $f(y): I R \rightarrow I R$ continuously differentiable

$$
\text { Then, } \operatorname{cov}(x ; b(y))=\mathbb{E}\left(\frac{\partial b(y)}{\partial y}\right) \operatorname{cov}(x ; y)
$$

The difference between the Rubinstein rule and our result comes from the function $b(x, y)$. We consider a function of two variables $x$ and $y$ and not a function of only one variable $y$.

case 1: $x$ and $y$ are perfectly correlated

Thus, $x$ and $y$ are linked by the following relation: $\frac{x-\mathbb{E}(x)}{\sigma_{x}}=\frac{y-\mathbb{E}(y)}{\sigma_{y}}$

We could directly apply the Rubinstein rule to cov $(x ; b(x, y))$

We obtain:

$$
\begin{aligned}
\operatorname{cov}(x ; b(x, y)) & =\mathbb{E}_{x}\left[\frac{\partial b(x, y)}{\partial x}+\frac{\sigma_{y}}{\sigma_{x}} \frac{\partial b(x, y)}{\partial y}\right] \operatorname{cov}(x, x) \\
& =\mathbb{E}_{x}\left[\frac{\partial b(x, y)}{\partial x}+\frac{\sigma_{y}}{\sigma_{x}} \frac{\partial b(x, y)}{\partial y}\right] \sigma_{x}^{2}
\end{aligned}
$$


case 2: $x$ and $y$ are independent

In that case, there is no relation between $x$ and $y$. We have to develop the covariance term.

$$
\begin{aligned}
\operatorname{cov}(x ; b(x, y))= & \mathbb{E}_{y}\left[\int_{x} x b(x, y) f(x \mid y) d x-\mathbb{E}(x) \mathbb{E}(b(x, y) \mid y)\right] \\
& =\mathbb{E}_{y}[\underbrace{\operatorname{cov}(x ; b(x, y) \mid y)}_{\text {term } 1}+(\mathbb{E}(x \mid y)-\mathbb{E}(x)) \mathbb{E}(b(x, y) \mid y)]
\end{aligned}
$$

We apply the Rubinstein rule to term 1 :

$$
\begin{aligned}
\operatorname{cov}(x ; b(x, y) \mid y) & =\mathbb{E}_{x}\left(\frac{\partial b(x, y)}{\partial x} \mid y\right) \operatorname{cov}(x ; x \mid y) \\
= & \mathbb{E}_{x}\left(\frac{\partial b(x, y)}{\partial x} \mid y\right) \operatorname{Var}(x \mid y) \\
= & \mathbb{E}_{x}\left(\frac{\partial b(x, y)}{\partial x} \mid y\right)\left(1-\rho^{2}\right) \sigma_{x}^{2}
\end{aligned}
$$

Then, we use the fact that $\mathbb{E}(x \mid y)=\mathbb{E}(x)+\rho \frac{\sigma_{x}}{\sigma_{y}}(y-\mathbb{E}(y))$.

Finally, we obtain:

$$
\begin{aligned}
\operatorname{cov}(x ; b(x, y)) & =\mathbb{E}_{y}\left[\mathbb{E}_{x}\left(\frac{\partial b(x, y)}{\partial x} \mid y\right)\left(1-\rho^{2}\right) \sigma_{x}^{2}+\rho \frac{\sigma_{x}}{\sigma_{y}}(y-\mathbb{E}(y)) \mathbb{E}_{x}(b(x, y) \mid y)\right] \\
& =\mathbb{E}\left(\frac{\partial b(x, y)}{\partial x}\right)\left(1-\rho^{2}\right) \sigma_{x}^{2}+\rho \frac{\sigma_{x}}{\sigma_{y}} \operatorname{cov}\left[y ; \mathbb{E}_{x}(b(x, y) \mid y)\right]
\end{aligned}
$$

Since $x$ and $y$ are independent, $\rho=0$. Thus, we obtain

$$
\operatorname{cov}(x ; b(x, y))=\mathbb{E}\left(\frac{\partial b(x, y)}{\partial x}\right) \sigma_{x}^{2}
$$

case 3: $x$ and $y$ are perfectly negatively correlated

In that case the link between $x$ and $y$ is: $\frac{x-\mathbb{E}(x)}{\sigma_{x}}=-\frac{y-\mathbb{E}(y)}{\sigma_{y}}$

and we obtain:

$$
\begin{aligned}
\operatorname{cov}(x ; b(x, y)) & =\mathbb{E}_{x}\left[\frac{\partial b(x, y)}{\partial x}-\frac{\sigma_{y}}{\sigma_{x}} \frac{\partial b(x, y)}{\partial y}\right] \operatorname{cov}(x, x) \\
& =\mathbb{E}_{x}\left[\frac{\partial b(x, y)}{\partial x}-\frac{\sigma_{y}}{\sigma_{x}} \frac{\partial b(x, y)}{\partial y}\right] \sigma_{x}^{2}
\end{aligned}
$$


By using the previous lemma we can determine the optimal hedging demand functions. The entrepreneur chooses a hedging level which maximizes his expected utility with respect to $h_{i}$.

$$
\max _{h_{i}} E V_{i}
$$

The first order condition is:

$$
\begin{gathered}
\mathbb{E}\left[\frac{\partial V_{i}}{\partial A_{i 1}} \frac{\partial A_{i 1}}{\partial h_{i}}\right]=0 \\
\Longleftrightarrow \mathbb{E}\left[\frac{\partial V_{i}}{\partial A_{i 1}}\left(A_{i 0}\left(p-\widetilde{p}_{i}\right)\right)\right]=0 \\
\Longleftrightarrow-\operatorname{cov}\left(\frac{\partial V_{i}}{\partial A_{i 1}} ; \widetilde{p}_{i}\right)=\mathbb{E}\left[\frac{\partial V_{i}}{\partial A_{i 1}}\right]\left(\mathbb{E} \tilde{p}_{i}-p\right)
\end{gathered}
$$

We can note that $-\operatorname{cov}\left(\frac{\partial V_{i}}{\partial A_{i 1}} ; \widetilde{p}_{i}\right)$ is positive. We know from proposition 1 , that $\frac{\partial V_{i}}{\partial A_{i 1}}$ is decreasing in $A_{i 1}$. But, $A_{i 1}$ is increasing in $\widetilde{p}_{i}$. Thus, when $\widetilde{p}_{i}$ increases, $A_{i 1}$ also increases, and then $\frac{\partial V_{i}}{\partial A_{i 1}}$ decreases. The covariance between $\frac{\partial V_{i}}{\partial A_{i 1}}$ and $\widetilde{p}_{i}$ is negative.

To develop the covariance term, we use lemma 3 in the different cases under consideration.

case 1: $\widetilde{p}_{i}$ and $\widetilde{p}_{j}$ are perfectly correlated

The link between $\widetilde{p}_{i}$ and $\widetilde{p}_{j}$ is: $\frac{\widetilde{p}_{i}-\mathbb{E}\left(\widetilde{p}_{i}\right)}{\sigma_{i}}=\frac{\widetilde{p}_{j}-\mathbb{E}\left(\widetilde{p}_{j}\right)}{\sigma_{j}}$

By using the lemma 3, we have:

$$
\operatorname{cov}\left(\frac{\partial V_{i}}{\partial A_{i 1}}, \widetilde{p}_{i}\right)=\mathbb{E}\left[\frac{\partial^{2} V_{i}}{\partial A_{i 1}^{2}} \frac{\partial A_{i 1}}{\partial \widetilde{p}_{i}}+\frac{\sigma_{j}}{\sigma_{i}} \frac{\partial^{2} V_{i}}{\partial A_{i 1} \partial A_{j 1}} \frac{\partial A_{j 1}}{\partial \widetilde{p}_{j}}\right] \operatorname{Var}\left(\widetilde{p}_{i}\right)
$$

By replacing the covariance term in the expression

$$
\begin{aligned}
& -\operatorname{cov}\left(\frac{\partial V_{i}}{\partial A_{i 1}} ; \widetilde{p}_{i}\right)-\mathbb{E}\left[\frac{\partial V_{i}}{\partial A_{i 1}}\right]\left(\mathbb{E} \widetilde{p}_{i}-p\right)=0 \text { we have: } \\
& -\mathbb{E}\left[\frac{\partial^{2} V_{i}}{\partial A_{i 1}^{2}} \frac{\partial A_{i 1}}{\partial \widetilde{p}_{i}}+\frac{\sigma_{j}}{\sigma_{i}} \frac{\partial^{2} V_{i}}{\partial A_{i 1} \partial A_{j 1}} \frac{\partial A_{j 1}}{\partial \widetilde{p}_{j}}\right] \operatorname{Var}\left(\widetilde{p}_{i}\right)-\left(\mathbb{E} \widetilde{p}_{i}-p\right) \mathbb{E}\left(\frac{\partial V_{i}}{\partial A_{i 1}}\right)=0
\end{aligned}
$$

We know that: 


$$
\begin{aligned}
\frac{\partial A_{i 1}}{\partial \widetilde{p}_{i}} & =\left(1-h_{i}\right) A_{i 0} \\
\text { and } \frac{\partial A_{j 1}}{\partial \widetilde{p}_{j}} & =\left(1-h_{j}\right) A_{j 0}
\end{aligned}
$$

By substitution in the above expression, we obtain:

$$
\begin{aligned}
h_{i}\left(h_{j}\right) & =1+\frac{A_{j 0}}{A_{i 0}} \frac{\mathbb{E}\left(\frac{\partial^{2} V_{i}}{\partial A_{i 1} \partial A_{j 1}}\right)}{\mathbb{E}\left(\frac{\partial^{2} V_{i}}{\partial A_{i 1}^{2}}\right)} \frac{\sigma_{j}}{\sigma_{i}}\left(1-h_{j}\right) \\
& +\frac{1}{A_{i 0}} \frac{\mathbb{E}\left(\frac{\partial V_{i}}{\partial A_{i 1}}\right)}{\mathbb{E}\left(\frac{\partial^{2} V_{i}}{\partial A_{i 1}^{2}}\right)} \frac{\mathbb{E} \widetilde{p}_{i}-p}{\sigma_{i}^{2}}
\end{aligned}
$$

case 2: $\widetilde{p}_{i}$ and $\widetilde{p}_{j}$ are independent

By using the lemma 3, we have:

$$
\operatorname{cov}\left(\frac{\partial V_{i}}{\partial A_{i 1}}, \widetilde{p}_{i}\right)=\mathbb{E}\left[\frac{\partial^{2} V_{i}}{\partial A_{i 1}^{2}} \frac{\partial A_{i 1}}{\partial \widetilde{p}_{i}}\right] \sigma_{i}^{2}
$$

By replacing the covariance term in the expression:

$$
\begin{aligned}
& -\operatorname{cov}\left(\frac{\partial V_{i}}{\partial A_{i 1}} ; \widetilde{p}_{i}\right)-\mathbb{E}\left[\frac{\partial V_{i}}{\partial A_{i 1}}\right]\left(\mathbb{E} \widetilde{p}_{i}-p\right)=0 \text { we have: } \\
& -\mathbb{E}\left[\frac{\partial^{2} V_{i}}{\partial A_{i 1}^{2}} \frac{\partial A_{i 1}}{\partial \widetilde{p}_{i}}\right] \sigma_{i}^{2}-\left(\mathbb{E}_{p_{i}}-p\right) \mathbb{E}\left(\frac{\partial V_{i}}{\partial A_{i 1}}\right)=0
\end{aligned}
$$

We know that:

$$
\frac{\partial A_{i 1}}{\partial \widetilde{p}_{i}}=\left(1-h_{i}\right) A_{i 0}
$$

By substitution in the above expression, we obtain:

$$
h_{i}\left(h_{j}\right)=1+\frac{1}{A_{i 0}} \frac{\mathbb{E}\left(\frac{\partial V_{i}}{\partial A_{i 1}}\right)}{\mathbb{E}\left(\frac{\partial^{2} V_{i}}{\partial A_{i 1}^{2}}\right)} \frac{\mathbb{E} \widetilde{p}_{i}-p}{\sigma_{i}^{2}}
$$


case 3: $\widetilde{p}_{i}$ and $\widetilde{p}_{j}$ are perfectly negatively correlated

The link between $\widetilde{p}_{i}$ and $\widetilde{p}_{j}$ is: $\frac{\widetilde{p}_{i}-\mathbb{E}\left(\widetilde{p}_{i}\right)}{\sigma_{i}}=-\frac{\widetilde{p}_{j}-\mathbb{E}\left(\widetilde{p}_{j}\right)}{\sigma_{j}}$

By using the lemma 3 , we have:

$$
\operatorname{cov}\left(\frac{\partial V_{i}}{\partial A_{i 1}}, \widetilde{p}_{i}\right)=\mathbb{E}\left[\frac{\partial^{2} V_{i}}{\partial A_{i 1}^{2}} \frac{\partial A_{i 1}}{\partial \widetilde{p}_{i}}-\frac{\sigma_{j}}{\sigma_{i}} \frac{\partial^{2} V_{i}}{\partial A_{i 1} \partial A_{j 1}} \frac{\partial A_{j 1}}{\partial \widetilde{p}_{j}}\right] \operatorname{Var}\left(\widetilde{p}_{i}\right)
$$

By replacing the covariance term in the expression :

$$
\begin{aligned}
& -\operatorname{cov}\left(\frac{\partial V_{i}}{\partial A_{i 1}} ; \widetilde{p}_{i}\right)-\mathbb{E}\left[\frac{\partial V_{i}}{\partial A_{i 1}}\right]\left(\mathbb{E} \widetilde{p}_{i}-p\right)=0 \text { we have: } \\
& -\mathbb{E}\left[\frac{\partial^{2} V_{i}}{\partial A_{i 1}^{2}}\left(1-h_{i}\right) A_{i 0}-\frac{\sigma_{j}}{\sigma_{i}} \frac{\partial^{2} V_{i}}{\partial A_{i 1} \partial A_{j 1}}\left(1-h_{j}\right) A_{j 0}\right] \operatorname{Var}\left(\widetilde{p}_{i}\right)-\left(\mathbb{E} \widetilde{p}_{i}-p\right) \mathbb{E}\left(\frac{\partial V_{i}}{\partial A_{i 1}}\right)=0
\end{aligned}
$$

By replacing in the above expression $\frac{\partial A_{i 1}}{\partial \tilde{p}_{i}} \frac{\partial A_{j 1}}{\partial \tilde{p}_{j}}$ by their respective value, we obtain $h_{i}\left(h_{j}\right)$ :

$$
\begin{aligned}
h_{i}\left(h_{j}\right) & =1-\frac{A_{j 0}}{A_{i 0}} \frac{\mathbb{E}\left(\frac{\partial^{2} V_{i}}{\partial A_{i 1} \partial A_{j 1}}\right)}{\mathbb{E}\left(\frac{\partial^{2} V_{i}}{\partial A_{i 1}^{2}}\right)} \frac{\sigma_{j}}{\sigma_{i}}\left(1-h_{j}\right) \\
& +\frac{1}{A_{i 0}} \frac{\mathbb{E}\left(\frac{\partial V_{i}}{\partial A_{i 1}}\right)}{\mathbb{E}\left(\frac{\partial^{2} V_{i}}{\partial A_{i 1}^{2}}\right)} \frac{\mathbb{E}_{\tilde{p}_{i}}-p}{\sigma_{i}^{2}}
\end{aligned}
$$

By using $\rho$, we have:

$$
\begin{aligned}
h_{i}\left(h_{j}\right) & =1+\rho \frac{A_{j 0}}{A_{i 0}} \frac{\mathbb{E}\left(\frac{\partial^{2} V_{i}}{\partial A_{i 1} \partial A_{j 1}}\right)}{\mathbb{E}\left(\frac{\partial^{2} V_{i}}{\partial A_{i 1}^{2}}\right)} \frac{\sigma_{j}}{\sigma_{i}}\left(1-h_{j}\right) \\
& +\frac{1}{A_{i 0}} \frac{\mathbb{E}\left(\frac{\partial V_{i}}{\partial A_{i 1}}\right)}{\mathbb{E}\left(\frac{\partial^{2} V_{i}}{\partial A_{i 1}^{2}}\right)} \frac{\mathbb{E} \widetilde{p}_{i}-p}{\sigma_{i}^{2}}
\end{aligned}
$$

\section{Appendix 3:}

Since we consider a quadratic form for the value function $V_{i}$, we could write

$$
\begin{aligned}
V_{i} & =c t e+a A_{i 1}+b A_{j 1}-c A_{i 1}^{2}-d A_{i 1} A_{j 1}-e A_{j 1}^{2} \\
& =c t e+a A_{i 1}+b A_{j 1}-c\left(A_{i 1}+\frac{d}{c} A_{j 1}\right)^{2}+e^{\prime} A_{j 1}^{2}
\end{aligned}
$$


Firm i's entrepreneur wants to maximize his expected income.

$$
\begin{aligned}
E V_{i} & =c t e+a E A_{i 1}+b E A_{j 1}-c E\left(A_{i 1}+\frac{d}{c} A_{j 1}\right)^{2}+e^{\prime} E A_{j 1}^{2} \\
& =c t e+a E A_{i 1}+b E A_{j 1}-c\left(E A_{i 1}+\frac{d}{c} E A_{j 1}\right)^{2}-c \operatorname{Var}\left(A_{i 1}+\frac{d}{c} A_{j 1}\right)+e^{\prime} E A_{j 1}^{2}
\end{aligned}
$$

One term of the entrepreneur 's hedging demand corresponds to the term which minimizes $\operatorname{Var}\left(A_{i 1}+\frac{d}{c} A_{j 1}\right)$ with respect to $h_{i}$.

To write the value function $V_{i}$, as we do above, we have to compute the second order limited development of $V_{i}$. We find then, that $d=\frac{1}{2} \frac{\partial^{2} V_{i}}{\partial A_{i 1} \partial A_{j 1}}$ and $c=\frac{1}{2} \frac{\partial^{2} V_{i}}{\partial A_{i 1}^{2}}$.

The first order condition with respect to the variance term is:

$$
2 A_{i 0}^{2}\left(1-h_{i}\right) \sigma_{i}^{2}=2 \operatorname{cov}\left(A_{i 0}\left(p-\widetilde{p}_{i}\right) ; \frac{\frac{\partial^{2} V_{i}}{\partial A_{i 1} \partial A_{j 1}}}{\frac{\partial^{2} V_{i}}{\partial A_{i 1}^{2}}} A_{j 0}\left(p h_{j}+\left(1-h_{j}\right) \widetilde{p_{j}}\right)\right)
$$

After computations, we find that the solution for $\rho \in\{-1 ; 0 ; 1\}$ is:

$$
h_{i}=1+\rho \frac{A_{i 0}}{A_{j 0}} \frac{\frac{\partial^{2} V_{i}}{\partial A_{i V_{i}} \partial A_{j 1}}}{\frac{\partial^{2} V_{i}}{\partial A_{i 1}^{2}}} \frac{\sigma_{i}}{\sigma_{j}}\left(1-h_{j}\right)
$$

with $\rho$ defined as the correlation coefficient between $\widetilde{p_{i}}$ and $\widetilde{p_{j}}$. This corresponds to the first term of lemma 1.

\section{Appendix 4: proof of proposition 2}

From lemma 1, we know that for $\rho \in\{1,0,-1\}$

$$
h_{i}\left(h_{j}\right)=1+\rho \frac{A_{j 0}}{A_{i 0}} \frac{\mathbb{E}\left(\frac{\partial^{2} V_{i}}{\partial A_{i 1} \partial A_{j 1}}\right)}{\mathbb{E}\left(\frac{\partial^{2} V_{i}}{\partial A_{i 1}^{2}}\right)} \frac{\sigma_{j}}{\sigma_{i}}\left(1-h_{j}\right)+\frac{1}{A_{i 0}} \frac{\mathbb{E}\left(\frac{\partial V_{i}}{\partial A_{i 1}}\right)}{\mathbb{E}\left(\frac{\partial^{2} V_{i}}{\partial A_{i 1}^{2}}\right)} \frac{\mathbb{E} \widetilde{p}_{i}-p}{\sigma_{i}^{2}}
$$

A ssume $h_{j}$ given.

Consider the function $f\left(h_{i}\right)$ defined by:

$$
f\left(h_{i}\right)=h_{i}-\frac{1}{A_{i 0}} \frac{\mathbb{E}\left(\frac{\partial V_{i}}{\partial A_{i 1}}\right)}{\mathbb{E}\left(\frac{\partial^{2} V_{i}}{\partial A_{i 1}^{2}}\right)} \frac{\mathbb{E} \widetilde{p}_{i}-p}{\sigma_{i}^{2}}
$$




$$
\frac{d f\left(h_{i}\right)}{d h_{i}}=1+\frac{\left(\mathbb{E} \widetilde{p}_{i}-p\right)^{2}}{\sigma_{i}^{2}}>0
$$

We see that $f\left(h_{i}\right)$ is increasing in $h_{i}$.

For $\rho=1, f\left(h_{i}\right)=1+$ a positive term

For $\rho=0, f\left(h_{i}\right)=1$

For $\rho=-1, f\left(h_{i}\right)=1+$ a negative term

Thus, as $f\left(h_{i}\right)$ is increasing in $h_{i}$ for $h_{j}$ given, we have:

$h_{i}^{\text {aggregated shocks }} \geq h_{i}^{\text {independent shocks }} \geq h_{i}^{\text {perfectly negatively correlated shocks }}$

\section{Appendix 5: First results of comparative statics}

1. When the variance of the spot price $\sigma_{i}^{2}$ increases

By using the implicit function theorem, for $\sigma_{j}^{2}$ given, we obtain the following

$$
\begin{aligned}
\frac{\partial h_{i}}{\partial \sigma_{i}^{2}} & =-\frac{1}{2} \rho \frac{A_{j 0}}{A_{i 0}} \frac{\mathbb{E} \frac{\partial^{2} V_{i}}{\partial A_{i 1} \partial A_{j 1}}}{\mathbb{E} \frac{\partial^{2} V_{i}}{\partial A_{i 1}^{2}}} \frac{\sigma_{j}}{\sigma_{i}^{3}}\left(1-h_{j}\right) \text { Term A } \\
& -\frac{1}{A_{i 0}} \frac{\mathbb{E} \frac{\partial V_{i}}{\partial A_{i 1}} \frac{\mathbb{E}_{p_{i}}-p}{\partial A_{i 1}^{2}}}{\left(\sigma_{i}^{2}\right)^{2}} \text { Term B }
\end{aligned}
$$

Term A represents the effect of $\sigma_{i}^{2}$ on the interaction effect. In the substitute case (in the complement case), this term is negative (positive) for the aggregated shocks case, equals to 0 for the independent shocks case and positive (negative) for the perfectly negatively correlated shocks case.

Term B represents the effect of $\sigma_{i}^{2}$ on the risk premium effect. This term is always positive.

2. When the firm $i$ 's date 0 amount of cash $A_{i 0}$ increases

By using the implicit function theorem, we obtain 


$$
\underbrace{-\frac{\rho A_{j 0} \mathbb{E}\left(\frac{\partial^{2} V_{i}}{\partial A_{i 1} \partial A_{j 1}}\right) \sigma_{j}\left(1-h_{j}\right)}{A_{i 0}^{2} \mathbb{E}\left(\frac{\partial^{2} V_{i}}{\partial A_{i 1}^{2}}\right) \sigma_{i}}-\underbrace{-\frac{\frac{\partial h_{i}}{\partial A_{i 0}}=}{\operatorname{Term~B}^{2}}}_{1+\frac{\left(\mathbb{E} \tilde{p}_{i}-p\right)^{2}}{\sigma_{i}^{2}}}}_{\text {Term A }}
$$

Term A represents the effect of $A_{i 0}$ on the interaction effect. In the substitute case (in the complement case), term $A$ is negative (positive) when shocks are aggregated, does not exist in the independent shocks case and is positive (negative) when shocks are perfectly negatively correlated.

Term $\mathrm{B}$ represents the effect of $A_{i 0}$ on the risk premium effect. It is always positive.

3. When the firm $j$ 's date 0 amount of cash $A_{j 0}$ increases

By using the implicit function theorem, we obtain

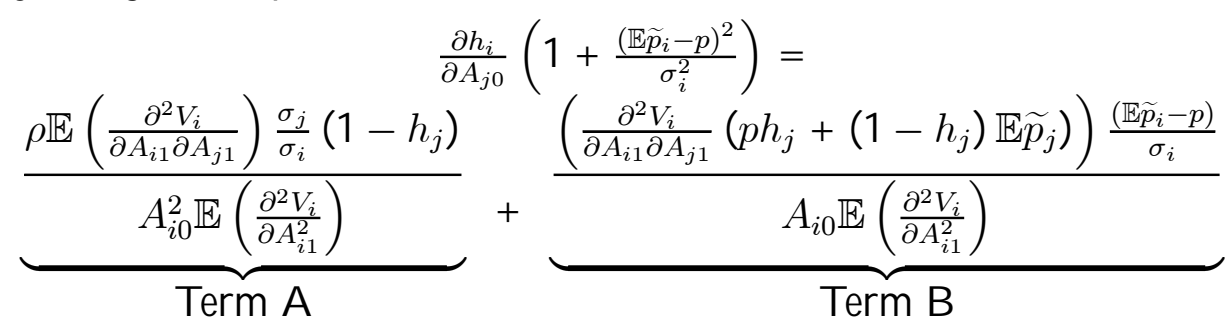

Term A represents the effect of $A_{j 0}$ on the interaction effect. In the substitute case (in the complement case), term $A$ is positive (negative) when shocks are aggregated, does not exist in the independent shocks case and is negative (positive) when shocks are perfectly negatively correlated.

Term $\mathrm{B}$ represents the effect of $A_{j 0}$ on the risk premium effect. It is positive for the substitute case and negative for the complement case.

4. When the private benefit $B$ of one entrepreneur increases

At the optimum, we have the following relationship

$$
\frac{\partial V_{i}}{\partial A_{i 1}}=\frac{B}{\Delta P} \frac{\partial I_{i}}{\partial A_{i 1}}-1
$$


Thus, at the optimum we have

$$
\frac{\partial h_{i}}{\partial B}=\frac{\frac{1}{A_{i 0}} \frac{\frac{1}{\Delta P} \frac{\partial I_{i}}{\partial i_{i 1}}}{\mathbb{E} \frac{\partial^{2} \tilde{V}_{i}}{\partial A_{i 1}^{2}}} \frac{\mathbb{E} \tilde{p}_{i}-p}{\sigma_{i}^{2}}}{1+\frac{\left(\mathbb{E} \tilde{p}_{i}-p\right)^{2}}{\sigma_{i}^{2}}}<0
$$

Under the assumptions taken for proposition $1, \frac{\partial I_{i}}{\partial A_{i 1}}>0$. Therefore, $\frac{\partial h_{i}}{\partial B}<0$.

\section{Appendix 6: evolution of firm $i$ 's hedging demand with respect to firm $j$ 's hedging level}

The computations for the substitute and the complement cases are the same, only their interpretations change. Consequently, we distinguish the computations only for the different shocks we are interested in: aggregated shocks, independent shocks and perfectly negatively correlated shocks. The distinction comes from the value of $\rho$.

We have:

$$
\begin{aligned}
h_{i}\left(h_{j}\right) & =1+\rho \frac{A_{j 0}}{A_{i 0}} \frac{\mathbb{E}\left(\frac{\partial^{2} V_{i}}{\partial A_{i 1} \partial A_{j 1}}\right)}{\mathbb{E}\left(\frac{\partial^{2} V_{i}}{\partial A_{i 1}^{2}}\right)} \frac{\sigma_{j}}{\sigma_{i}}\left(1-h_{j}\right) \\
& +\frac{1}{A_{i 0}} \frac{\mathbb{E}\left(\frac{\partial V_{i}}{\partial A_{i 1}}\right)}{\mathbb{E}\left(\frac{\partial^{2} V_{i}}{\partial A_{i 1}^{2}}\right)} \frac{\mathbb{E} \widetilde{p}_{i}-p}{\sigma_{i}^{2}}
\end{aligned}
$$

and thus,

$$
\begin{aligned}
\frac{\partial h_{i}\left(h_{j}\right)}{\partial h_{j}} & =-\rho \frac{A_{j 0}}{A_{i 0}} \frac{\mathbb{E}\left(\frac{\partial^{2} V_{i}}{\partial A_{i 1} \partial A_{j 1}}\right)}{\mathbb{E}\left(\frac{\partial^{2} V_{i}}{\partial A_{i 1}^{2}}\right)} \frac{\sigma_{j}}{\sigma_{i}} \\
& +\frac{1}{A_{i 0}} \mathbb{E}\left[\frac{\partial^{2} V_{i}}{\partial A_{i 1}^{2}} \frac{\partial A_{i 1}}{\partial h_{i}} \frac{\partial h_{i}}{\partial h_{j}}+\frac{\partial^{2} V_{i}}{\partial A_{i 1} \partial A_{j 1}} \frac{\partial A_{j 1}}{\partial h_{j}}\right] \frac{1}{\mathbb{E}\left(\frac{\partial^{2} V_{i}}{\partial A_{i 1}^{2}}\right)} \frac{\mathbb{E} \widetilde{p}_{i}-p}{\sigma_{i}^{2}}
\end{aligned}
$$


Since the value function $V_{i}$ is quadratic, its second derivatives are constant. Thus, $\frac{\partial h_{i}\left(h_{j}\right)}{\partial h_{j}}$ could be written

$$
\begin{aligned}
& \frac{\partial h_{i}}{\partial h_{j}}\left[1+\frac{\left(p-\mathbb{E}_{i} \widetilde{p}_{i}\right)^{2}}{\sigma_{i}^{2}}\right] \\
& =-\rho \frac{A_{j 0}}{A_{i 0}} \frac{\mathbb{E}\left(\frac{\partial^{2} V_{i}}{\partial A_{i 1} \partial A_{j 1}}\right)}{\mathbb{E}\left(\frac{\partial^{2} V_{i}}{\partial A_{i 1}^{2}}\right)} \frac{\sigma_{j}}{\sigma_{i}}-\frac{A_{j 0}}{A_{i 0}} \frac{\frac{\partial^{2} V_{i}}{\partial A_{i 1} \partial A_{j 1}}}{\mathbb{E}\left(\frac{\partial^{2} V_{i}}{\partial A_{i 1}^{2}}\right)} \frac{\left(\mathbb{E} \widetilde{p}_{j}-p\right)\left(\mathbb{E} \widetilde{p}_{i}-p\right)}{\sigma_{i}^{2}}
\end{aligned}
$$

Thus, for $\rho=1$, we characterize the derivative expression for the aggregated shocks case.

For $\rho=0$, we characterize the derivative expression for the independent shocks case.

For $\rho=-1$, we characterize the derivative expression for the perfectly negatively correlated shocks case.

Therefore, we have characterized the derivative expression for all the cases we are interested in.

\section{Appendix 7: proof of proposition 6 and 7}

Proof. We have:

- $\frac{\partial h_{i}}{\partial h_{j}} \geq 0$, for the aggregated shocks and independent shocks cases

- for the perfectly negatively correlated shocks case, $\frac{\partial h_{i}}{\partial h_{j}}$ could be positive or negative

- $h_{i}^{\text {aggregated shocks }}(0)<h_{i}^{\text {independant shocks }}(0)<h_{i}^{\text {perfectly negatively correlated shocks }}(0)$

- $h_{i}^{\text {aggregated shocks }}(1)=h_{i}^{\text {independant shocks }}(1)=h_{i}^{\text {perfectly negatively correlated shocks }}(1)<1$

- the reaction functions are linear

- we make the implicit assumption that $\left|\mathbb{E}\left(\frac{\partial^{2} V_{i}}{\partial A_{i 1} \partial A_{j 1}}\right)\right|<\left|\mathbb{E}\left(\frac{\partial^{2} V_{i}}{\partial A_{i 1}^{2}}\right)\right|$ 
We distinguish two cases:

First case: $\frac{\partial h_{i}}{\partial h_{j}} \geq 0, \forall \rho \in\{-1,0,1\}$.

thus we have:

\section{figure $3 a$}

The symmetric Nash equilibria are unique and respect the proposition 6

Second case: $\frac{\partial h_{i}}{\partial h_{j}} \geq 0$ for the aggregated shocks and independent shocks cases and $\frac{\partial h_{i}}{\partial h_{j}} \leq 0$ for the perfectly negatively correlated shocks case

\section{figure $3 b$}

As shown in the figure $3 \mathrm{~b}$, the symmetric Nash equilibria are unique and respect proposition 7. 